\title{
Potentials of Airborne Hyperspectral AVIRIS-NG Data in the Exploration of Base Metal Deposit-A Study in the Parts of Bhilwara, Rajasthan
}

\author{
Arindam Guha 1,*, Uday Kumar Ghosh ${ }^{2}$, Joyasree Sinha ${ }^{2}$, Amin Beiranvand Pour ${ }^{3}{ }^{(1)}$, Ratnakar Bhaisal ${ }^{2}$,

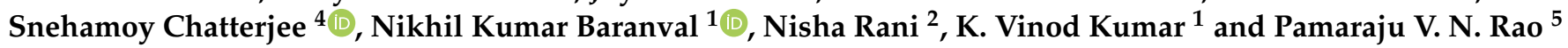 \\ 1 Geosciences Group, National Remote Sensing Centre, Indian Space Research Organization, Balanagar, \\ Hyderabad 500010, India; nikhilkumar_b@nrsc.gov.in (N.K.B.); vinodkumar_k@nrsc.gov.in (K.V.K.) \\ 2 Photogeology and Remote Sensing Division, 29, Jawaharlal Nehru Road, Geological Survey of India, \\ Kolkata 700016, India; uday.ghosh@gsi.gov.in (U.K.G.); joyasree.sinha@gsi.gov.in (J.S.); \\ ratnakar.bhaisal@gsi.gov.in (R.B.); nisha.rani@gsi.gov.in (N.R.) \\ 3 Institute of Oceanography and Environment (INOS), Universiti Malaysia Terengganu (UMT), \\ Kuala Nerus 21030, Malaysia; beiranvand.pour@umt.edu.my \\ 4 Department of Geological and Mining Engineering and Science, Michigan Technological University, \\ Houghton, MI 49931, USA; schatte1@mtu.edu \\ 5 National Remote Sensing Centre, Indian Space Research Organization, Hyderabad 500010, India; \\ rao_pvn@nrsc.gov.in \\ * Correspondence: arindam_g@nrsc.gov.in
}

\section{check for} updates

Citation: Guha, A.; Kumar Ghosh, U.; Sinha, J.; Pour, A.B.; Bhaisal, R.; Chatterjee, S.; Kumar Baranval, N.; Rani, N.; Kumar, K.V.; Rao, P.V.N. Potentials of Airborne Hyperspectral AVIRIS-NG Data in the Exploration of Base Metal Deposit-A Study in the Parts of Bhilwara, Rajasthan. Remote Sens. 2021, 13, 2101. https://doi.org/ $10.3390 /$ rs13112101

Academic Editor: Thomas Cudahy

Received: 1 April 2021

Accepted: 22 May 2021

Published: 27 May 2021

Publisher's Note: MDPI stays neutral with regard to jurisdictional claims in published maps and institutional affiliations.

Copyright: (c) 2021 by the authors. Licensee MDPI, Basel, Switzerland. This article is an open access article distributed under the terms and conditions of the Creative Commons Attribution (CC BY) license (https:/ / creativecommons.org/licenses/by/ $4.0 /)$.
Abstract: In this study, we have processed the spectral bands of airborne hyperspectral data of Advanced Visible Infrared Imaging Spectrometer-Next Generation (AVIRIS-NG) data for delineating the surface signatures associated with the base metal mineralization in the Pur-Banera area in the Bhilwara district, Rajasthan, India.The primaryhost rocks of the $\mathrm{Cu}, \mathrm{Pb}, \mathrm{Zn}$ mineralization in the area are Banded Magnetite Quartzite (BMQ), unclassified calcareous silicates, and quartzite. We used ratio images derived from the scale and root mean squares (RMS) error imagesusing the multi-range spectral feature fitting (MRSFF) methodto delineate host rocks from the AVIRIS-NG image. The False Color Composites (FCCs) of different relative band depth images, derived from AVIRIS-NG spectral bands, were also used for delineating few minerals. These minerals areeither associated with the surface alteration resulting from the ore-bearing fluid migration orassociated with the redoxcontrolled supergene enrichments of the ore deposit.The results show that the AVIRIS-NG image products derived in this study can delineate surface signatures of mineralization in 1:10000 to 1:15000 scales to narrow down the targets for detailed exploration. This study alsoidentified the possible structural control over the knownsurface distribution of alteration and lithocap minerals of base metal mineralizationusing the ground-based residual magnetic anomaly map. This observationstrengthens the importance of the identified surface proxiesas an indicator of mineralization. $\mathrm{X}$-ray fluorescence analysis of samples collectedfromselected locations within the study area confirms the $\mathrm{Cu}-\mathrm{Pb}-\mathrm{Zn}$ enrichment. The sulfide minerals were also identified in the microphotographs of polished sections of rock samples collected from the places where surface proxies of mineralization were observed in the field. This study justified the investigation to utilize surface signatures of mineralization identified using AVIRIS-NG dataand validated using field observations, geophysical, geochemical, and petrographical data.

Keywords: AVIRIS-NG; base metal; continuum removed spectral bands; ground magnetic data; banded magnetite quartzite; multi-rangespectral feature fitting; relative band depth

\section{Introduction}

Advanced Visible Infrared Imaging Spectrometer-Next Generation (AVIRIS NG) data have been successfully utilized for delineatingthe surface signatures of different mineral de- 
posits [1-3]. Utilities of AVIRIS-NG data for deriving spectral index image composites to identify different rock types in the sedimentary province have also been reported [1,4-6]. Studies also indicated the advantages of hyperspectral bands of AVIRIS-NG data over the multispectral bands of sensorssuch as Advanced Spaceborne Thermal Emission and Reflection Radiometer (ASTER) for mineral mapping due to superior spectral, spatial, and radiometric resolution of airborne hyperspectral data like AVIRIS-NG data [7]. In this respect, comparative analysisof AVIRIS-NG and ASTER data confirmed the potential of airborne AVIRIS-NG data over ASTER data for delineating surface exposures of kimberlite and chromite, as these rocks generally have few isolated and small-sized surface exposures [1]. The past studies also reported airborne hyperspectral image (AVIRIS) over spaceborne hyperspectral data EO-1 Hyperion [8,9]. However, there are limited records on the comparative analysis of AVIRIS-NG data with advanced multispectral data such as Landsat- 08 and Sentinel-02 sensors. A recent study showed comparative utilization of airborne hyperspectral data, anddifferent spaceborne multispectral data, including Landsat, ASTER, and Sentinel, for mineral mapping [10]. The integrations of multi-sensors data for mineral mapping were also reported in the literature [11,12]. Free availability of AVIRIS-NG data covering significant geological provinces of India would definitely attract researchers to utilize AVIRIS-NG data for geological application for a few important geological provinces [13].

The exploration of the base metal deposit is always challenging using remote sensing data. A few studies were carried out where surface signatures of base metal deposits were delineated using spaceborne hyperspectral datawith moderate spatial resolution [14-16]. Still, records are limited on utilizing high spatial resolution airborne hyperspectral data for detecting subtle or patchy surface signatures. The small and patchy surface signatures of base metal mineralization are difficult to capture by spaceborne multispectral and hyperspectral data due to having low spatial and spectral resolution [1]. Many of the base metal deposits are known for their poor surface expression [17]. Some of them are identified with the surface presence of sporadically developed Gossans. The formation of Gossans above sulfide deposits is governed by the $\mathrm{pH}$ of the reaction system and alsoby the presence of Fe minerals with the sulfides [17]. Surface minerals, in an assemblage with goethite, hematite, and malachite, are formed above the $\mathrm{pH}$ greater than 6.5 , while native $\mathrm{Cu}$ are formed at a $\mathrm{pH}$ lower than 6 in Gossanized lithocap [17]. However, many times, Gossans are poorly developed [18]. Many of the $\mathrm{Cu}$ deposits hosted by Fe-oxides (magnetite and or hematite) are characterized by albitization, formation of $\mathrm{K}$ feldspar, and kaolinization [19]. Detection of these patchy and small-sized surface signatures of base metal mineralization is essential to understand the overall distribution of supergene enrichment, and hydrothermal alteration zones for identifying the areas with superior concentrations of metals. The conjugate utilization of surface signatures of mineralization and the subsurface information of ore genetic controls, revealed from ground geophysical data, might be beneficial to identify localized enrichment of metals.

Exploration companies extensively utilize all the modern airborne hyperspectral sensors from globally acclaimed, commercial data providers such as HyMap, Compact Airborne Spectrographic Imager (CASI), SWIR Airborne Spectrographic Imager (SASI), AISA-EAGLE (400-970 nm) and AISA-HAWK (970-2500 nm) -Airborne Imaging Spectrometer for Applicat, and HySpexto prepare large-scale detailed alteration and lithological maps. The role of these datasets in exploration highlights the importance of airborne hyperspectral data in narrowing down an exploration target. The major advantage of the utilization of AVIRIS-NG, or similar high-quality airborne hyperspectral data, is their high spectral, radiometric, and spatial resolution. It helps to map surface signatures of mineralization in its capability to detect the subtle spectral anomalies of localized or spatially restricted targets (e.g., alterations of mineral assemblages, oxide/hydroxide minerals occurring as the cap rock above the mineral enriched zones occurring down the depth). The spectral contrast of these minerals to background rocks will be minimal if the spatial resolution of hyperspectral acquisition is made from spaceborne sensors, which generally have poor spatial resolution, radiometric resolution, and signal-to-noise ratio (SNR)compared to the airborne hyperspectral data. The alteration map prepared from the airborne hyperspectral data isvery detailed. It provides valuable input 
for developing a localized exploration model in a specific mineralized province. However, most airborne hyperspectral data have a limited spatial extent, which are not sufficient to identify the spatial extension of geological controlling parameters of the ore genetic process (e.g., the regional extent of the geological structure, the host rock responsible for concentrating and hosting mineral deposits, etc.). Therefore, it is essential that the localized and large-scale map, identifying altered rock or lithocap as the proxy of mineralization, should be analyzed using regional data to improve the exploration model and strategy for mineralexploration. A mineralizedprovince may have a few discrete mineral-enriched blocks and can be controlled by the ore genetic process. This can be achieved if we use airborne hyperspectral data with other geological or spectral datasets witha larger swath.

The potential use of a large-scale map of "surface mineralization signatures" for finding the pathways of localized metal enrichment necessitates the utilization of Aairborne hyperspectral data using AVIRIS-NG sensor to derive some spectrally enhanced products to identify the cap rock and associated altered rock indicative of enrichment of base metal deposit. In this study, an attempt has been made to synergize the high-resolution map of surface signatures of metal enrichment with the high-resolution geophysical anomaly map to identify the locales of metal enrichment. Some of these surface enrichments may lead to the discovery of a pocket load for mining.

The study area is exposed to the tropical dry climate in the state of Rajasthan, which issituated in thenorthwestern part of India. Most of the rocks were exposed on the surface with the limited surface covers (covered with vegetation, soil). Thus, the site is ideal for carrying out remote sensing-based study for detecting surface mineralization signatures using airborne hyperspectral data (Figure 1a). Previous research attributed to the mineralization of Pur-Banera is syngenetic with other sediment-hosted $\mathrm{Pb}-\mathrm{Zn}$ mineral deposits in Rampur-Agucha, Zawar, and Rajpura-Dariba deposits [13]. It has also been identified that the base metal deposits are associated with the longitudinal structure [20]. Therefore, spectral mapping of supergene and altered minerals are conjugated with the ground magnetic data processing to relate surface proxies of mineralization with the structural control.

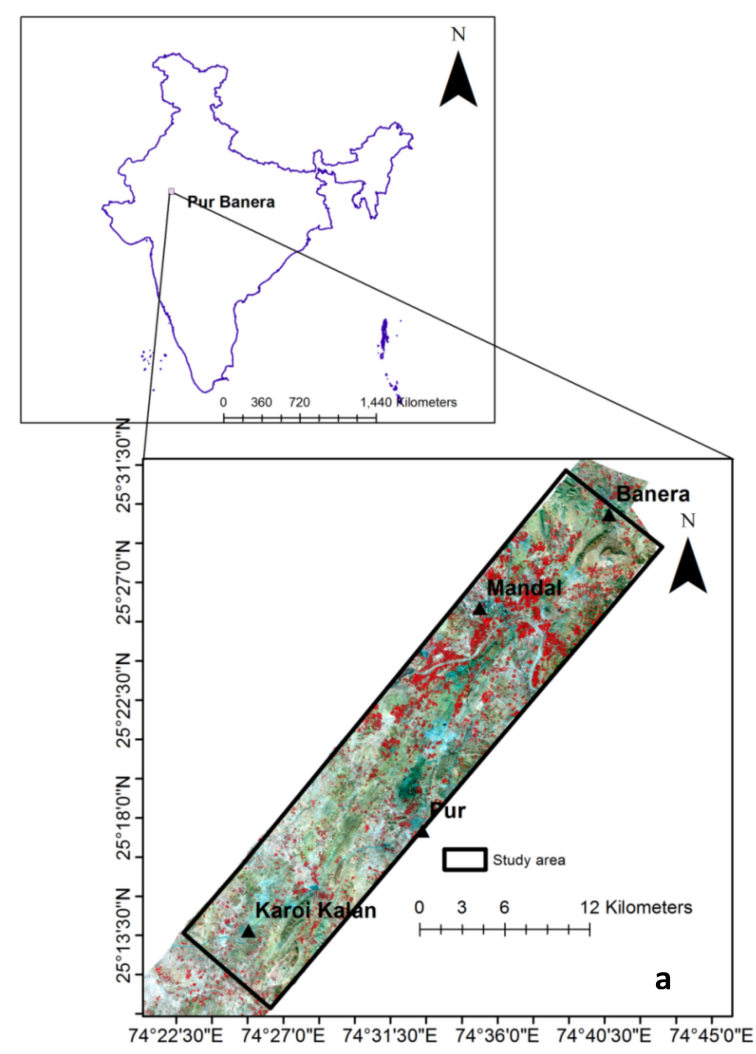

Figure 1. Cont. 


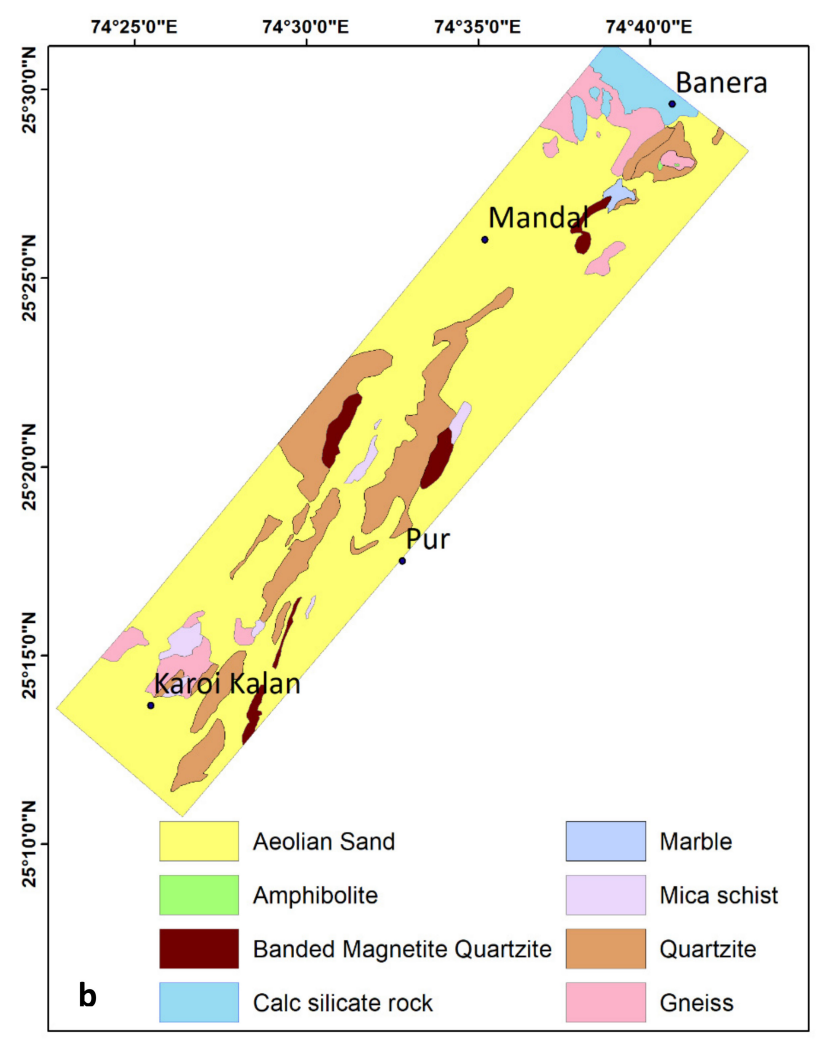

Figure 1. (a) AVIRIS-NG false-color composite (FCC)map of Pur-Banera area. In the figure, AVIRIS-NG image strips from two successive airborne acquisitions are shown. A few important locations within the study area are also shown. For FCC image, Red $=850 \mathrm{~nm}$, Green $=650 \mathrm{~nm}$ and Blue $=560 \mathrm{~nm}$ bands were used; (b) Lithological map showing the disposition of major rock types.

\section{Geology}

The Pur-Banera belt is characterized by the $80 \mathrm{~km}$ long mineralized belt from Banera to Rewara. The rocks of the study area are chemogenic in origin and, the main rock units of the area are calcareous silicate, Banded Magnetite Quartzite (BMQ), quartzite, amphibole rich marble, garnetiferous schist, ferruginous quartzite, amphibolite, garnetiferous mica-schist, etc., [21].

The Pur-Banera Group is part of the Bhilwara Supergroup of the Lower Proterozoic age, and the sediments were believed to be deposited in a pull-apart basin [22]. The lower most stratigraphic unit of the area is known as the Pur Formation. This Formation is constituted with polymictic conglomerate, micaceous quartzite [23]. It is overlain by calcareous silicate of the Rewara Formation. The Rewara Formation, in turn, is overlain by an inter-banded sequence of BMQ, calcareous silicate rock, and garnet biotite schist that constitutes the Tiranga Formation that forms the main hosts for sulfide mineralization $(\mathrm{Pb}-\mathrm{Zn})$. The $\mathrm{BMQ}$ is regarded as the marker lithounit for $\mathrm{Cu}, \mathrm{Pb}, \mathrm{Zn}$ deposits [23]. The uppermost lithologicalFormation of the study areais known as the Samodi Formation. Major litho-components of this formation are quartzite, mica schist, marble, and calcareous silicate [23]. In addition to the lithological control, the base metal mineralizationis also controlled by fault systems [16]. Base metal deposits of the study area and the reported occurrence of metal inthe adjoining regions are believed to be associated with the northnortheast (NNE)-south-southwest (SSW) to the northeast (NE)-southwest (SW) trending longitudinal structure [13]. Uranium mineralization was also reported in the study area, and it was associated with the quartzite of the Pur Formation [23].

Structurally, the Pur-Banera supracrustals were highly deformed with three phases of deformation (D1-D3); each of these deformation phaseshad imprinted their respective tectonic fabric [23]. The first deformation (D1) resulted in the formation of the NW-SE trending upright fold [23] from NE-SW-directed shortening. Subsequently, NNE-SSW- 
directed deformation (D2) contributed to the formation of west-northwest (WNW) - eastsoutheast (ESE) trending vertical folds [24]. Finally, asymmetrical folds developed due to dextral shearing directed along the north (N)-south (S)/NNE SSW trend at the final stage of deformation (D3) [24]. Therefore, thesegeological structures could have played an important role inremobilizing the ore minerals from host rock to concentrate them along with specific structural fabric [25]. It has been believed that the base metal depositswere formed by convective seawater circulation in zones of crustal extension that traversed the Aravalli Fold belt [25].In the study area, $\mathrm{Pb}-\mathrm{Zn}$ occurrences were reported at the eastern fringe of the study area, whereas Cu-rich zones were reported in the western fringe [26]. The lithological map of the study area was prepared following the method discussed in [1] and using the information acquired during the field survey, available geological literature, and textural, geomorphic, and tonal contrasts of different rocks observed in the AVIRIS-NG FCC image (Figure 1b). Cu deposits are reported in places such as Pur-Dariba, Gurla, Manpura, Banera forest, Devpura, Banera, Malikhera, Sanganer, Rajpura, Dhulikhera, and Gadan-ka-Khera, etc. [26,27]. On the other hand, known areas for $\mathrm{Pb}$ and $\mathrm{Zn}$ are Mahua Khurd, Devpura, and Tiranga Hill (South of Arjiya) [26,27].

\section{Materials and Methods}

3.1. Materials

\subsubsection{AVIRIS-NG Data}

The AVIRIS-NG hyperspectral sensor of the Jet Propulsion Laboratory (JPL), National Aeronautic and Space Administration (NASA), has been used to acquire hyperspectral data trending along the NE-SW direction in the Pur Banera mineralized belt. AVIRIS-NG has 425 narrow continuous spectral bands within the spectral domain of 380-2510 nm at a $5 \mathrm{~nm}$ interval (Table 1). The spectral datasets have high SNR (>2000@600 nm and $>1000 @ 2200 \mathrm{~nm}$ ) [6]. The sensor has a field of view (FOV) of 34 degrees and an Instantaneous Field of view (IFOV) of 1mrad [6]. The Ground Sampling Distance (GSD) vis-à-vis pixel resolution varies from $4 \mathrm{~m}$ from theflightaltitude of $4 \mathrm{~km}$ with a swath coverage of $10 \mathrm{~km}$. The AVIRIS-NG data were acquired using a B-200 aircraft of the National Remote Sensing Centre, India [6].

Table 1. Specification of AVIRIS-NG data.

\begin{tabular}{ccccc}
\hline S No. & Sensor & Spatial Resolution $(\mathbf{m})$ & Band & Band/Wavelength $(\mu \mathrm{m})$ \\
\hline 1 & $\begin{array}{c}\text { Airborne Visible/Infrared Imaging } \\
\text { Spectrometer- Next generation } \\
(\text { AVIRIS-NG) }\end{array}$ & 4 & 425 & $\begin{array}{c}0.38-2.510 \\
(\text { spectral sampling: } 5 \mathrm{~nm})\end{array}$ \\
\hline
\end{tabular}

Level 02 data products of AVIRIS-NG sensors were used in this study. Level 02 (surface reflectance product) data productswerederived from "at-sensor-radiance data" in real-time [6]. For deriving the Level 02 data product, the pixel-based atmospheric correction method was used with an assumption that the atmosphere is spatially invariant. The pixel-measured aerosol optical depth and water vaporconcentrationwere used for generating surface reflectance [6]. The pixel-based approach first derives atmospheric water vapor and aerosol optical depth at the pixel level from the top of the atmosphere (TOA) radiance, which serves as the input to the atmospheric correction models [6].

Atmospheric calibration was performedby implementinga modified physics-based atmospheric removal (ATREM) algorithm, which utilizes a large lookup table of precomputed scattering and transmission coefficients, indexed by parameters specifying the aircraft operating conditions at capture time [27].

\subsubsection{Spectral Datasets}

We used a Field spec3 spectroradiometer, manufactured by Analytical Spectral Devices (ASD) Inc. (Boulder, CO, USA), to collect the laboratory spectra of major rock samples. All 
the spectra were collected in the wavelength range of 325-2500 $\mathrm{nm}$. Spectra of the rocks were collected to use them as the reference to process AVIRIS-NG data. Five to six rock samples of each rock type were collected from the prominent surface exposures in the field for spectral data collection. The size of each rock sample was fixed using the size norms of the Jet Propulsion Laboratory [28-32].

\subsubsection{Ground Magnetic Data}

The Geological Survey of India carried out the magnetic survey under the National Geophysical Mission (NGPM) to support stage II and stage III (i.e., semi detail staged exploration) of exploration. The magnetic survey is a low-cost, rapid geophysical survey and is known for providing an idea of the geological structures and lithological variations. It is also indicative of the presence of certain mineral deposits. In this study, a Proton Precession Magnetometer (GSM 19T) (sensitivity $0.01 \mathrm{nT}$ ) was used to carry out a groundbased magnetic survey [33]. At the time of magnetic data collection, special care was taken to avoid different noises induced by certain anthropogenic activities of local origin (e.g., high tension power lines, concealed iron pipes dispersed for water supply, ironrich elements such as cars, etc.). In this study, a magnetic survey was carried out with a sampling interval of $100 \mathrm{~m}$, and the distance between two subsequent profile lines (which are trending along east-west) is $125 \mathrm{~m}$.

\subsubsection{X-ray Fluorescence (XRF) and Petrographical Data}

XRFis the fast and accurate non-destructive tool used for estimating the concentration of metals in the rock samples. In the present study, the Malvern Panalytical-Zetium Wavelength dispersive XRF(WDXRF) instrument was used [34]. Pressed powder pellets and fused beads were prepared from powdered samples, and then elements wereanalyzed using WDXRF) having a $4 \mathrm{kw}$ Rhodium anodetube. In the WDXRF, the X-ray tube irradiated the sample with high energy $X$-ray; fluorescence emanated from samples due to the interaction of the sample, and these $X$-rayswere measured by a wavelength dispersive detection system. The characteristic radiation coming from each element was identified using analyzed crystals, which separate the X-rays based on their wavelength [34]. The intensities of the respective $\mathrm{X}$-rays were also measured sequentially to estimate the concentration of metals.

The petrographical analysis of the rocks wascarried out under refracted light and reflected light conditions using an Olympus trinocular polarizing microscope (model: Olympus BX 51).

\subsection{Methods}

We have followed three major segments of the methods for identifying the surface signatures of mineralization using AVIRIS-NG data andvalidating the identified surface signatures. These three segments are: 1 . collection, processing of rock spectra, and mineralogical analysis of spectral features; 2 . AVIRIS-NG data processing and spectral mapping; 3. validation using XRF, ore microscopy, ground magnetic, and field data. Each segment hasdifferent sub-segments. A flow chart is used to illustrate the different segments and sub-segments of the methods to executethis research (Figure 2).

\subsubsection{Collection and Analysis of Rock Spectra}

We have collected samples of major rock types (e.g., BMQ, calcareoussilicates, quartzite, amphibolite, and mica schist). We analyzed the spectra of these rocks using the Fieldspec 3 spectrometer under laboratory conditions. The spectrometer has a spectral resolution of $3 \mathrm{~nm}$ within the spectral range of 350-1000 $\mathrm{nm}$ and $10 \mathrm{~nm}$ within the spectral domain of 1000-2500 nm [28].We collected the rock samples from the surfaceexposures. We havealso collected the samples of different rock types, which indicated the signature of surface mineralization(e.g., limonite/goethite is regarded as the cap rock of amineralized zone, and sericitised/calcite rich siliceous veins are the indicatorsof hydrothermal or late phase fluid activity). 


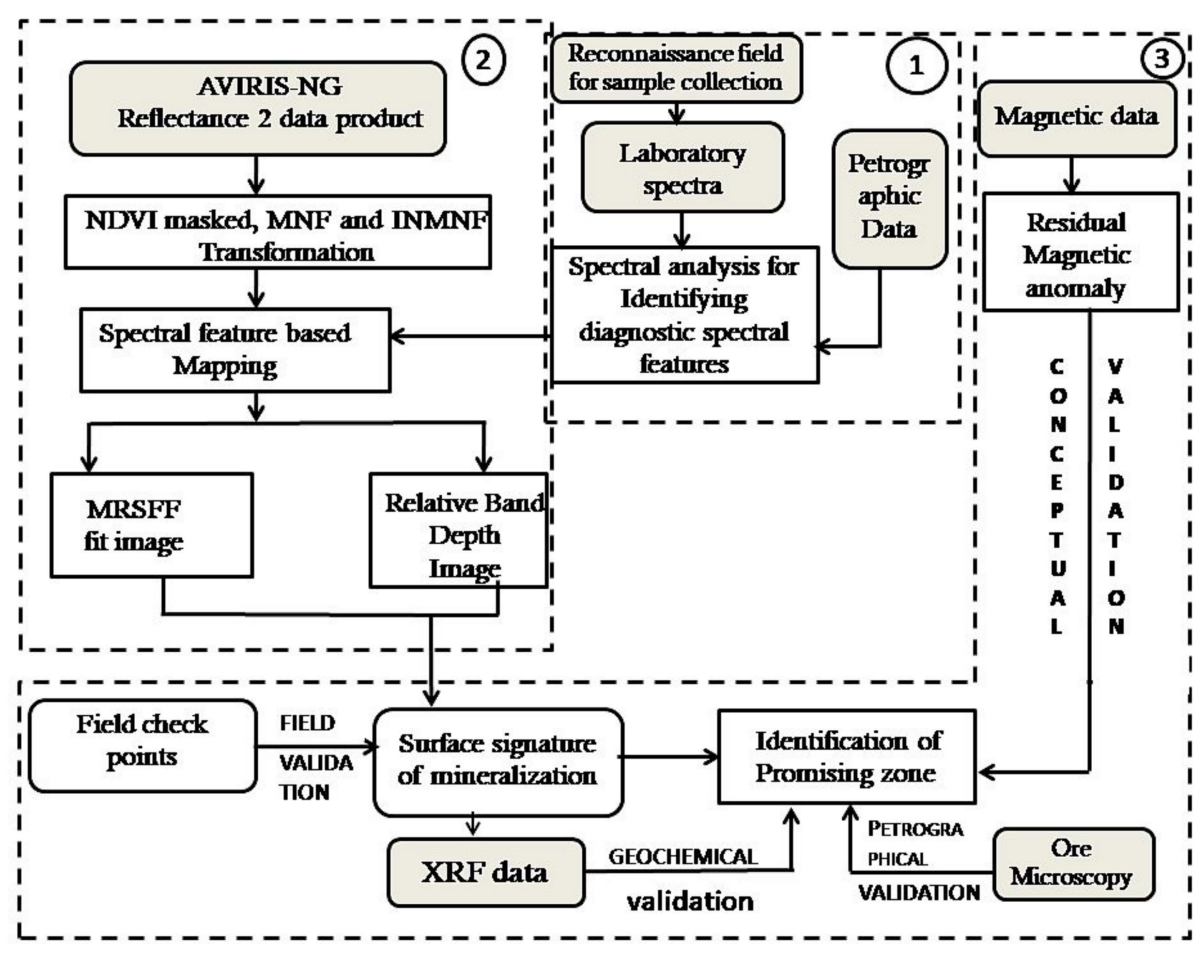

Figure 2. Flow chart showing the major steps followed in the study. In the flow chart, three major segments of the work are shown with dotted outline and numbers. The major segments in the methodology are 1: collection and rock spectra, and mineralogical analysis of spectral feature; 2. AVIRIS-NG data processing and spectral mapping; 3. validation using XRF, Ore microscopy, ground magnetic, and field data.

The rock samples were cut into rectangular blocks of 4 inch $\times 5$ inch to 5 inch $\times 7$ inch. The radiance spectra of the rock samples were collected using a halogen lamp and the foreoptics (i.e., optical fiber) witha 250-degree field of view. Subsequently, reflectance spectra of rock samples were derived by normalizing the sample radiance with the radiance of a fully Lambertian white plate [28-32].

The methodology for collecting the spectral profiles of different types of rocks and the analysis of these spectral profiles are documented in the literature [28,33-35]. Spectral profiles of three to four spots of each sample were recorded to incorporate the variability of spectral profiles across the sample, and subsequently, these observations were averaged to derive representative spectra of each rock sample. Averaging of spectral profiles provides the advantage of reducing the effect of noise imprinted on the spectral profile of therock samples. The representative laboratory spectrum of each rock sample was subsequently resampled to a wavelength range of AVIRIS-NG bands, andthespectra of all these rocks were plotted together to understand the respective spectral features of each rock type. The spectrum of each rock type was also compared with the spectra of dominant constituent minerals to understand how spectra of minerals have contributedto shaping the spectral feature of rock. In this regard, we used the mineralogical information of each rock derived from the petrographic analysis, and analyzed under refracted light (both under plainpolarized and cross-polarized conditions).

Amongstthese rocks, BMQ, calcareoussilicates, and quartzite aremainlyassociated with the base metal deposit. We used the spectra of these rocks andother associated rocks to delineate the spatial distribution of these rocks. We also used spectra of sericitised quartzite and carbonate-rich vein and goethite/Fe-oxides as the reference to identify these minerals on the surface, as these minerals are regarded as the surface proxies of base metal enrichment. These rock samples were collected from various locations whereminerals related to surface alteration were reported. 


\subsubsection{AVIRIS-NG Data Processing andSpectral Mapping}

AVIRIS-NG Level 02 data (reflectance data) were used in the study. Before attempting spectral enhancement of targets, prominent vegetation areas were masked using the normalized difference vegetation index (NDVI). The AVIRIS-NG-bands-NDVI image for each scene was thresholded to derive a mask band which was applied to AVIRIS NG scenes. The threshold value was selected iteratively by applying different thresholds on the scenes to ensure that the deciduous vegetation and crops present in the scenes were masked. We used AVIRIS NG bands with the wavelengths centered around $850 \mathrm{~nm}$ (Near infrared band) and $650 \mathrm{~nm}$ (for Red band) to derive NDVI. NDVI-based thresholding is used for vegetation masking because it demonstrated promising results in many of the previous studies on mineral exploration $[1,36]$.

Spectra of host rock and altered rock were resampled to the bandwidth of AVIRIS-NG spectral bands, which were used as the reference to implement the multi-range spectral feature fitting (MRSFF) method. Spectral feature fitting is a spectral matching algorithm, which uses the inherent absorption feature of the spectrum of interest and reference endmember spectrum for least squares matching. Different types of spectral matching methods have been discussed in the literature [37]. In MRSFF, the absorption features at various wavelength ranges are considered for estimating similarities between the target spectrum and the reference spectrum [38]. Many minerals have multiple absorption features, and these diagnostic features of different minerals may overlap. Therefore, we used the multirange spectral feature fitting method to identify the wavelength ranges of diagnosticand non-overlapping spectral features of each rock distinctly. We identified the diagnostic spectral feature of each rock with respect to the spectra of dominant constituent minerals. Mineralogy of rock was ascertained by petrographic analysis. The spectral range of the diagnostic feature of rock is identified from the continuum removed reference spectra of rocks. The spectral range of diagnostic absorption features was delimited by the wavelength of shoulders (localized reflectance maxima) on either side of the absorption minima of the spectral feature. The diagnostic spectral features of each rock were identified based on the comparison of the absorption feature of rock with the corresponding absorption feature of constituent minerals, which have prominent spectral features within the spectral domain of the AVIRIS-NG sensor. We used the width and depth of an absorption feature and the wavelength of absorption minima to estimate the relative abundance of the target $[39,40]$. Width is the distance measured at the inflection points occurring on either side of the absorption feature. Depth measures the distance between the deepest point of the absorption feature and the central point on a line joining the shoulders of the absorption feature. Once we estimated the least squares fit between the continuum removed AVIRIS-NG image and reference laboratory spectra of rocks using the MRSFF method, we derived the scale image by the fitted least squares model [38]. Subsequently, we derived the ratio of the scale image to root mean squares (RMS) error image of the least squares fit model, defined as "fit" image, for delineating the specific rock types. The fitimage signifies the pixel with high least squares values andminimum RMS error. Furthermore, we prepared the fit image foreach rock type to createan FCC image fordelineating rocks in the spatial domain.

Identification of the absorption feature and its spectral range guided by mineralogical knowledge would be helpful to detect the target effectively. In addition to deriving the MRSFF-based fit map of different rocks, we deriveda relative band depth image delineating different minerals, which are used as the surface proxy of metal enrichment. In the relative band depth image, spectral bands having their wavelength coinciding with the wavelength of shoulders and absorption minima of the individual diagnostic spectral feature of rock were used. The relative band depth image can be used to detect minerals associated with the lithocap rock and altered rock of sulfide mineralization [41]. Conjugate detection of host rocks and the surface imprints of mineralizationhave been implemented in this study to confirm the spatial association of prominent surface alteration and cap rock minerals within the extent of the host rock. The conjugate approach can then effectively narrow down the area for detailed mineralogical and petrographical analysis for further exploration. 


\subsubsection{Magnetic Data Processing}

The acquired magnetic data were subjected to diurnal and International Geomagnetic Reference Field (IGRF) corrections to derive the total field magnetic anomaly values. The magnetic anomaly values are then presented as a contour map using the minimum curvature gridding technique in Geosoft (Oasis Montaj version 8.3) software [42]. Unlike gravity anomalies, magnetic anomalies do not appear vertically above the anomalous body. It is asymmetric due to the dipolar behavior of the earth's magnetic field as we move away from the poles tothe equator $[43,44]$. This distortion in magnetic anomalies can be eliminated by a reduction-to-pole (RTP) transformation using various approaches [45-47]. The average inclination and declination of the study area are 37.67 and 0.39 , respectively. The total field magnetic anomaly data were reduced to a pole using a Fourier domain filtering technique [48] in Geosoft software to bring the symmetrical anomaly above the causative source. Further, the Gaussian regional/residual filtering technique was used to separate the regional and residual magnetic anomaly [49]. The residual magnetic anomaly was separated using a high pass filter at wavenumber $3 \mathrm{~km}$ to delineate the anomaly caused by shallow or near surface subsurface structures.

\subsubsection{XRF and Petrographical Analysis}

$\mathrm{XRF}$ is a widely used technique to quantify the concentration of elements by generatinghigh-energy photons from an X-ray source, which pass through primary filters to normalize their energy variability. Rock samples were milled to less than 230-mesh size for XRF analysis. A 4.5-g powder sample of -200 mesh size was taken in an aluminum cup of $40 \mathrm{~mm}$ diameter. A few drops of polyvinyl alcohol weremixedwith the powdered sample; subsequently, the mixture was transferred to a $40 \mathrm{~mm}$ aluminum cup and pressed for $5 \mathrm{~min}$ at $40,000 \mathrm{psi}$. Samples were also ignited at above $900^{\circ} \mathrm{C}$ to determine the loss of ignition. Photons are allowed to pass into a sample, and this, in turn, allows the energy of photons to get transferred to an inner-shell electron of an atom. X-Rays displace the electron from its preferred orbit, leaving an unstable atom. An electron from an outer orbital fills the vacancy in the lower orbital by releasing its energy in a fluoresced secondary $\mathrm{X}$-ray, unique to the element. Element concentrations are determined by the rate at which fluorescence of a detector in the spectrometer records secondary X-rays.XRF spectrum analysis was conducted using the methods described in the literature [50,51].

\section{Results}

We have processed two imaging strips of AVIRIS-NG data for the Pur-Banera area. The AVIRIS-imaging strips are aligned along the NE-SW direction, parallel to the trend of the Aravalli Group of rocks (Figure 1). The detailed steps followed to derive the study results are summarized in a flowchart (Figure 2). We have presented the results of the study in different segments to align with the proposed methods.

\subsection{SpectralAnalysis to Identify the Diagnostic Spectral Features of Different Rocks and the Altered Rocks}

Spectral analysis was carried out to identify the diagnostic spectral features of rocks and analyze their mineralogical significance [52]. Spectral analysis was used as the basisfor deriving the AVIRIS-NG-based image products (Figure 3). We identified the prominent spectral features of the four most dominating rock types: calcareous silicates, quartzite, amphibolites, and BMQ. These rocks are associated with the surface imprints of mineralization in the study area. We found that calcareous silicates, amphibolite, and sericitized quartzite have their diagnostic absorption features in the short-wave infrared (SWIR) domain, whereas $\mathrm{BMQ}$ has its diagnostic spectral feature in the near-infrared domain (Figure 3a).

We found that the spectral feature of the calcite governed the spectral feature of calcareous silicates at $2330 \mathrm{~nm}$ (Figure 3b). Similarly, the main diagnostic spectral feature of amphibolite was governed by the hornblende with the absorption feature having wavelength minima at 2320 and $2375 \mathrm{~nm}$, respectively (Figure 3c). Sheared quartzite has sericite 
as the major constituent mineral; therefore, the diagnostic spectral feature of sericite was considered as the basis for identifying the spectral feature of sericite bearing quartzite (Figure 3d). We identified that the spectral feature of BMQ was governed by the magnetite; however, the spectral depth of BMQ was smaller than the spectral depth of magnetite at the same wavelength (Figure 3e).
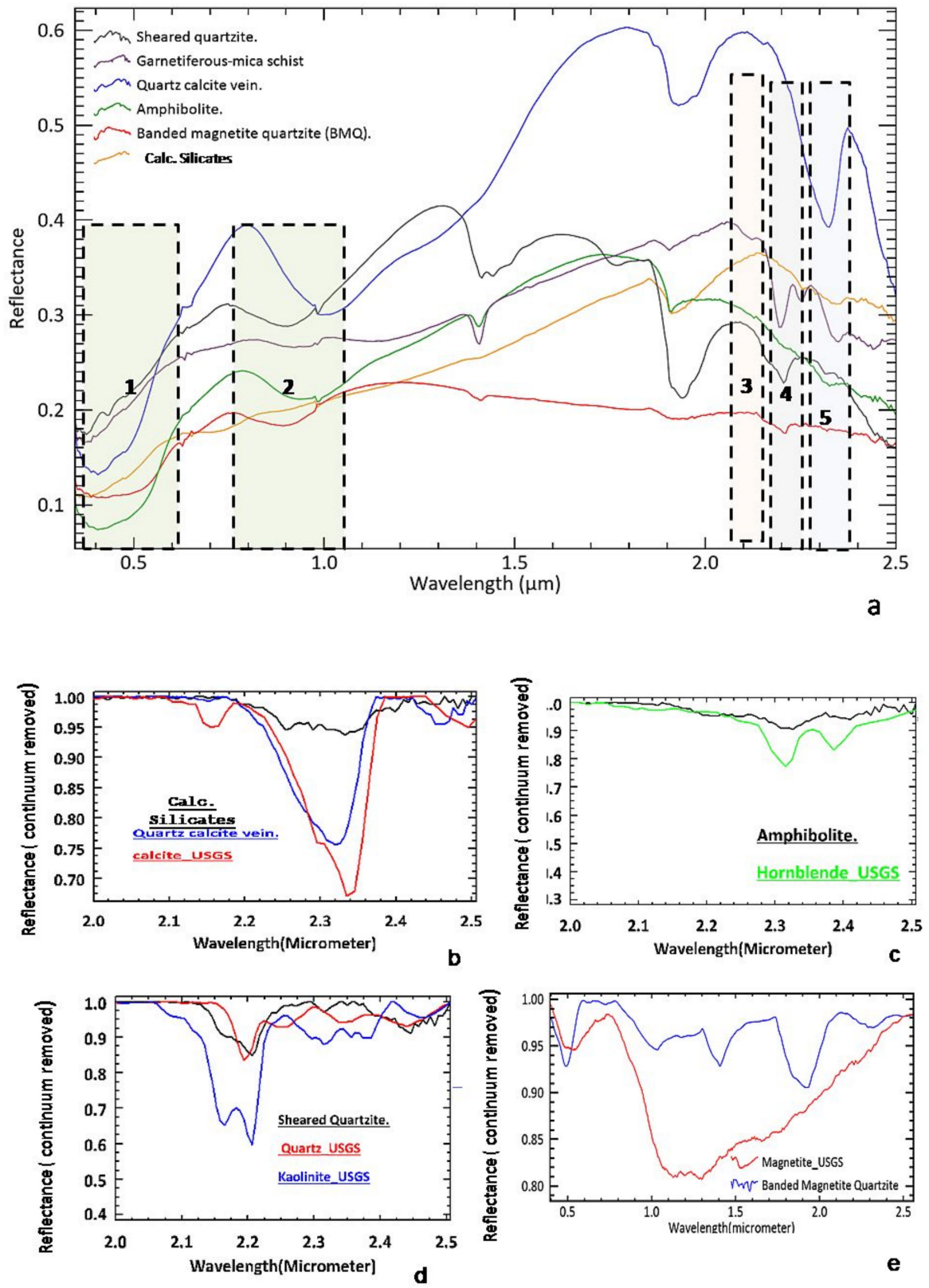

Figure 3. (a) Plot of representative spectral profiles of main rock types of the study area. In the plot, each box is used to illustrate schematically the spectral domain of few diagnostic absorption features of main rock type of the study area. Box 1: Wavelength domain of diagnostic spectral feature of BMQ. Box 2: Wavelength domain of diagnostic spectral feature of quartzite (which are sericite rich and sheared). Box 3: Wavelength domain of diagnostic spectral feature of carbonate rich calcareous silicates. Box 4 and 5: Wavelength domain of diagnostic spectral feature of amphibolite. Plots (b-e) of representative spectrum of each rock type with the spectra of their constituent minerals are presented to show how the spectral features of dominant and spectrally diagnostic minerals influence the spectral features for differentrock types: $b$. calcareous silicates; c. amphibolite. $d=$ sheared quartzite; and $\mathrm{e}=$ banded magnetite quartzite. 
We analyzed the optical thin section of representative rock samples of quartzite, amphibolite, BMQ, and calcareoussilicates to ascertain their respective mineral constituents andto relate spectra of constituent minerals with the rock (Figures 4 and 5). We identified the mineral constituent of all four studied rocks from the thin section analysis. The presence of sulfide minerals was confirmed based on optical thick section studies of rock samples collected around the areas with the presence of surface proxies of mineralization (Figures 4 and 5).

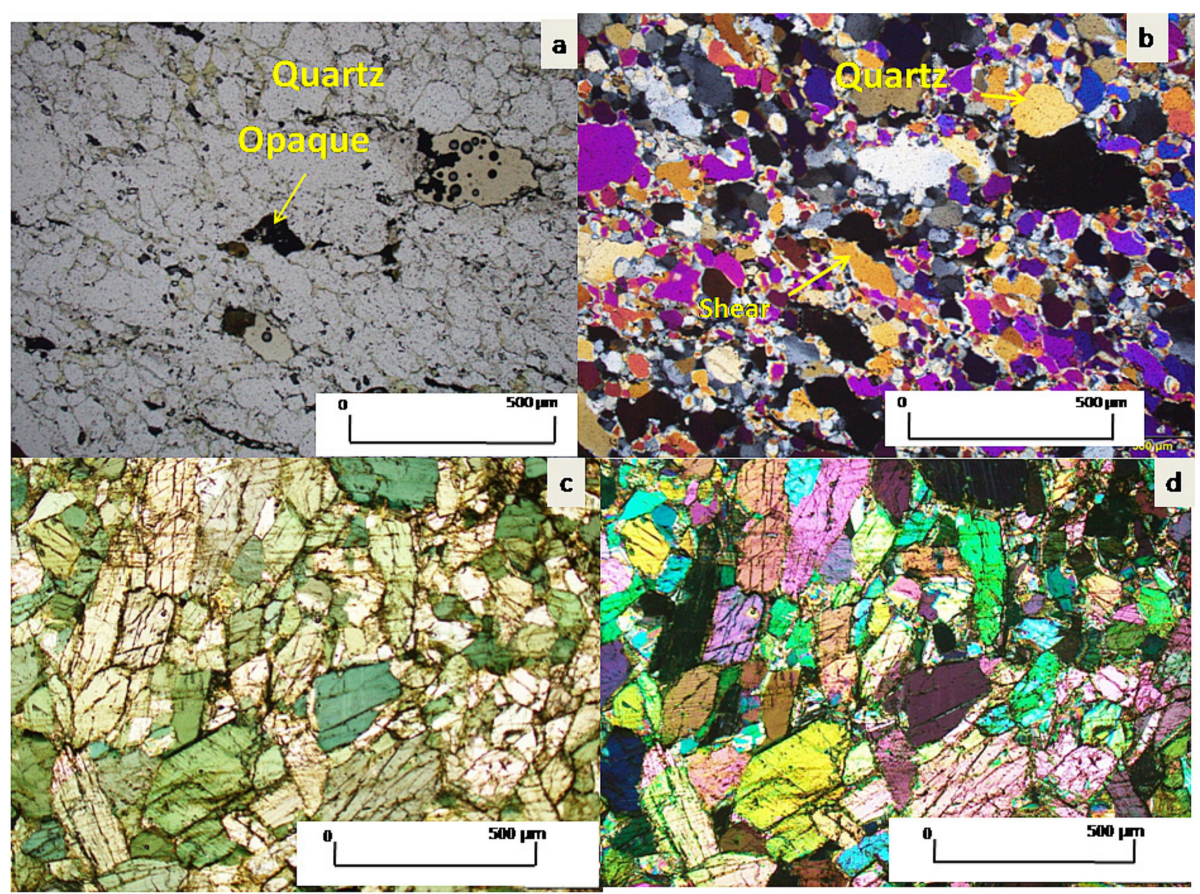

Figure 4. (a) Plain-polarized optical thin section of quartzite. (b) Cross-polarized optical thin section of quartzite in which evidence of shearing is prominent. (c) Plain-polarized optical thinsection of amphibolite. (d) Cross-polarized optical thin section of amphibolite.

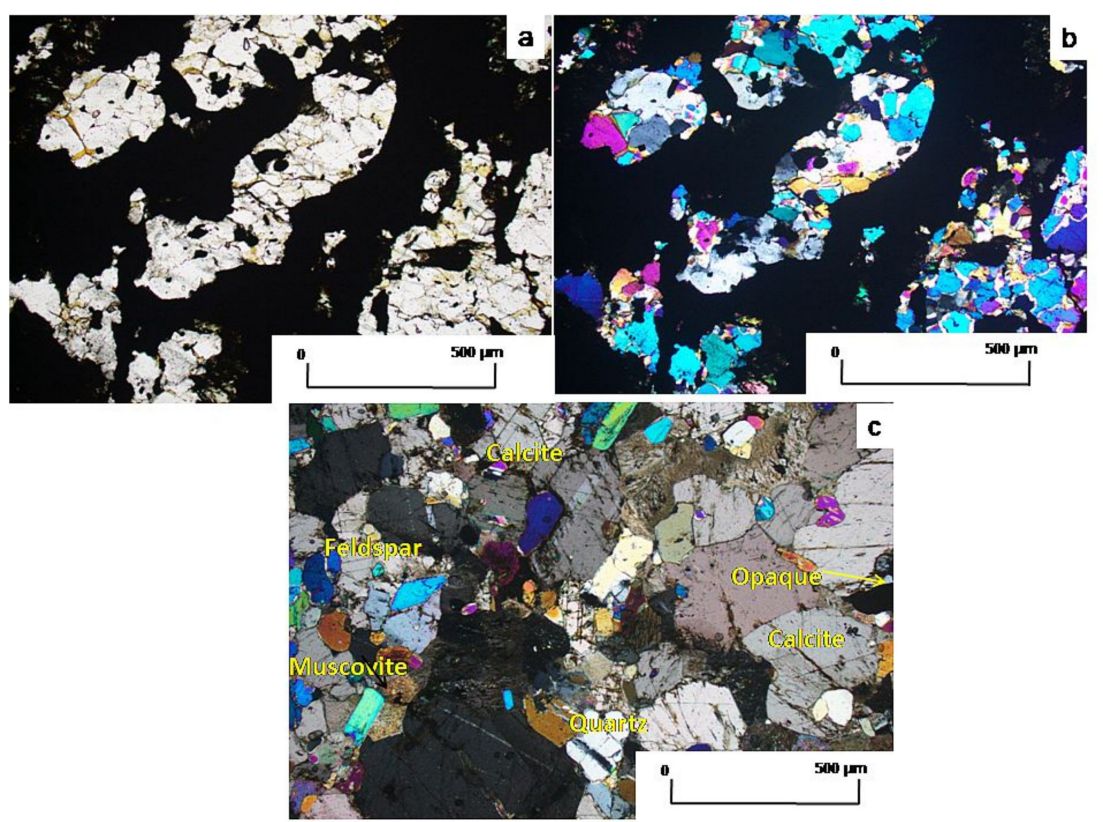

Figure 5. (a) Plain-polarized optical thin section of banded magnetite quartzite (BMQ) under microscope. (b) Cross-polarized optical thin section of BMQ. In this thin section, magnetite appears dark. (c) Cross-polarized optical thin section of calcareous silicate rocks. 
We also analyzed the spectra of major minerals (e.g., calcite, sericite, limonite, goethite, and kaolinite) from the United States Geological Survey (USGS) spectral library after resampling to the bandwidth of AVIRIS-NG sensor bands [53]. Delineation of these minerals is important as metal mineralization in the study area has the surface imprints of Gossans (i.e., presence of goethite and limonite, sericiitized zone, calcite rich veining, etc.). We analyzed spectra of calcite, sercitie, and goethite and used the diagnostic spectral feature of these minerals (Figure 6) to propose a few relative band depth (RBD) images. The RBD images were used to delineate surface minerals of the study area, as documented in Table 2 [54].

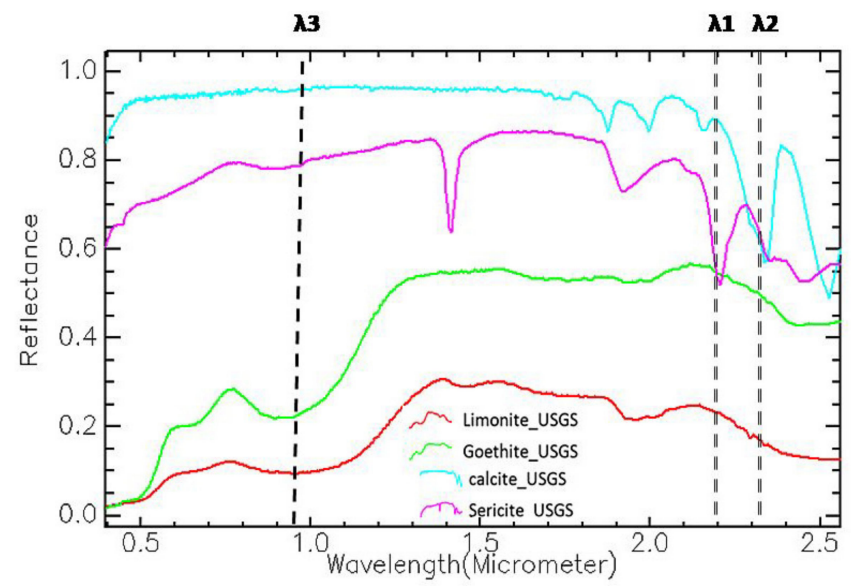

Figure 6. AVIRIS-NG spectral band resampled spectral profiles of the minerals associated with surface mineralization signatures. $\lambda 1$ to $\lambda 4$ refers to the absorption features of different minerals. $\lambda 1=$ wavelength minima of diagnostic spectral feature of kaolinite. $\lambda 2=$ wavelength minima of diagnostic spectral feature of sericite. $\lambda 3=$ Wavelength minima of diagnostic spectral feature of calcite. $\lambda 4=$ wavelength minima of diagnostic spectral feature of goethite and limonite.

Table 2. Spectral bands used for deriving AVIRIS-NG-based relative band depth image for different minerals associated with alteration and supergene enrichment.

\begin{tabular}{ccccc}
\hline & & \multicolumn{3}{c}{ Spectrometric Parameter } \\
\cline { 3 - 5 } S. No. & Mineral & $\begin{array}{c}\text { Wavelength of } \\
\text { Shoulder } \mathbf{1}(\mathbf{n m})\end{array}$ & $\begin{array}{c}\text { Wavelength of } \\
\text { Shoulder 2 (nm) }\end{array}$ & $\begin{array}{c}\text { Wavelength of } \\
\text { Abs-min (nm) }\end{array}$ \\
\hline 1 & Calcite & 2184 & 2389 & 2339 \\
3 & Illite/sericite & 2144 & 2284 & 2204 \\
4 & Goethite & 767 & 1222 & 937 \\
\hline
\end{tabular}

\subsection{AVIRIS-NG Data Processing and Spectral Mapping for Mapping Host Rock and Surface Signatures of Mineralization}

We identified spectrometric parameters of each diagnostic feature of rock. The width and depth of the spectral features were calculated from continuum removed spectra within the spectral domain of spectral feature (Figure 7). We investigated different MRSFF image composites and RBD imagesfor detecting host rocks and proxy-minerals indicative of surface mineralization, respectively, in different parts of the study area. In the Gurla area, we found that the sericitized zone is associated with BMQ. It was ascertained based on the conjugate analysis of the RBD image compositeofcalcite, sericite, and iron oxideandthe MRSFFfit image of BMQ (Figure 8a,b). The sericitized zone wasidentified as a green-coloredunit within BMQ (Figure $8 \mathrm{a}, \mathrm{b}$ ). BMQ occurs as a structural hill in this area (Figure 8c). In this area, we identified pegmatitic intrusionwithin BMQand the highly weathered sericitized zone, which were validated in the field (Figure 9a,b). The surface imprint of the geological structure, i.e., a linear brittle structure, is identified in the FCC image ofAVIRIS-NG spectral bands. These linear brittle structures could be the conduits along which the late phase liquid had migrated, and ore had preferentially concentrated (Figure 8c). 


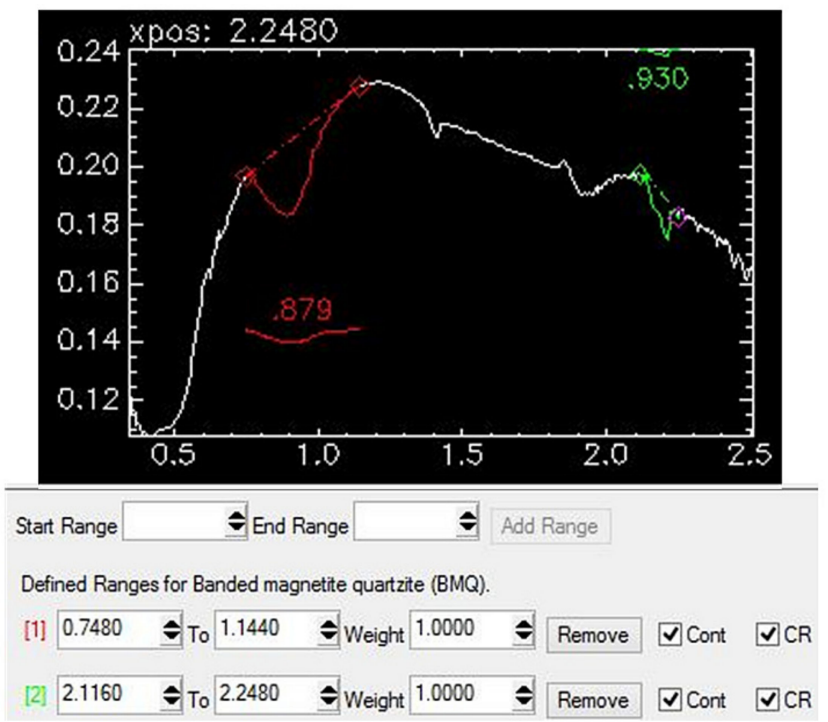

Figure 7. Graphical representation of how spectral range and other spectrometric parameters such as the width and depth of the diagnostic absorption features of each rock type are used to implement multi-range spectral feature fitting algorithm.

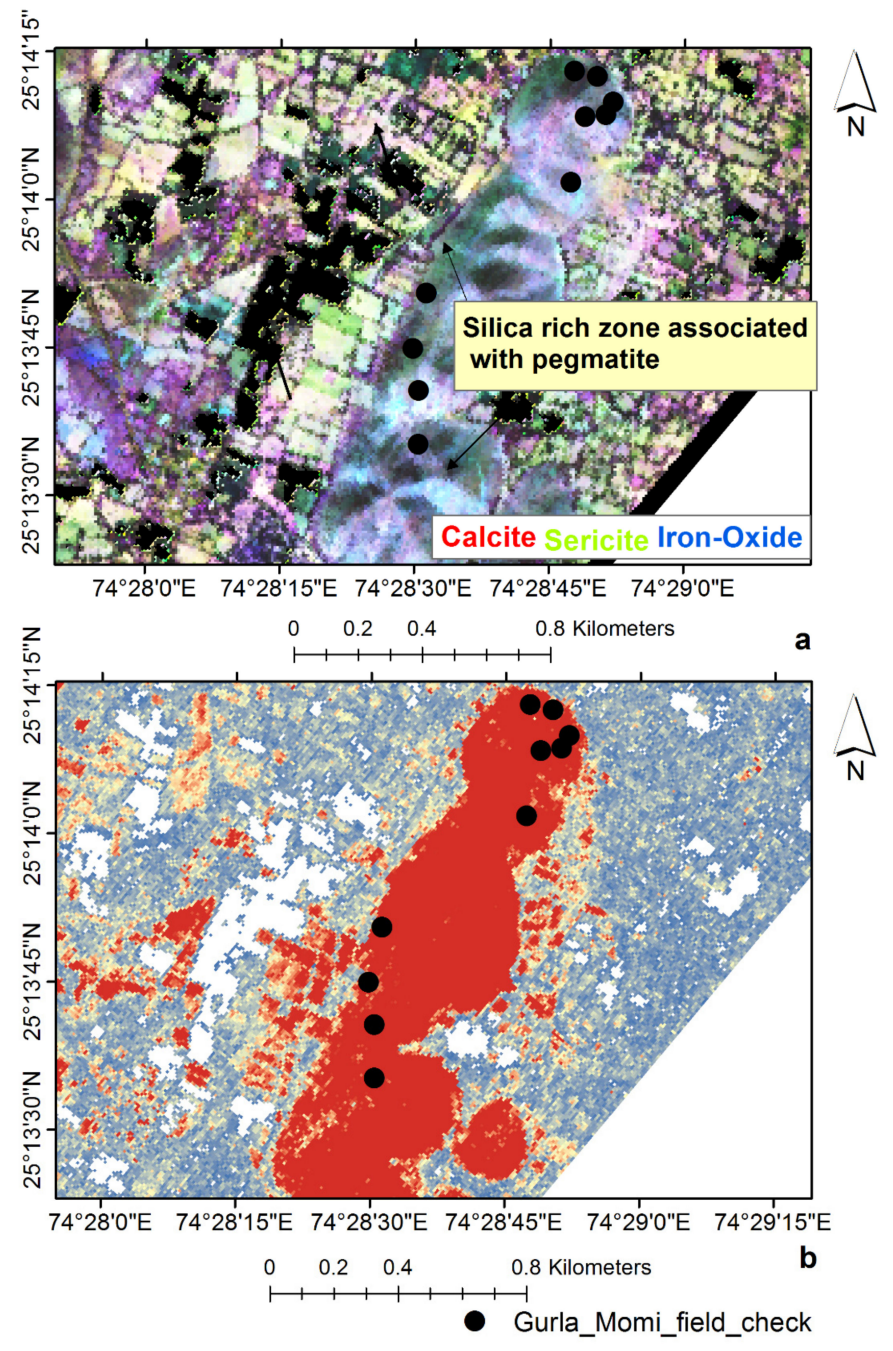

Figure 8. Cont. 


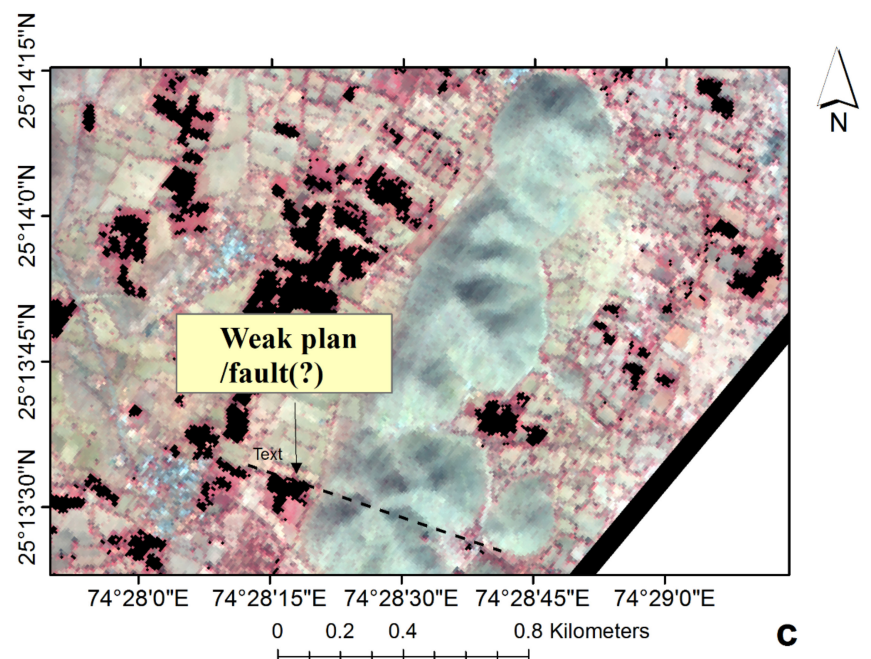

Figure 8. (a) FCC image of calcite, sericite, and Gossan relative band depth (RBD) to delineate the presence of pegmatite and silica rich, sericitized zones associated with BMQ in GurlaMomi area. (b) Surface exposures of Banded Magnetite Quartzite (BMQ)-rich zones identified in thresholdedfit image (derived as the ratio of scale and RMS error image of MRSFF method). (c) FCC image composite of AVIRIS-NG bands of the same area are also shown to show. In this image, Red $=950 \mathrm{~nm}$, Green $=650 \mathrm{~nm}$, and Blue $=560 \mathrm{~nm}$.

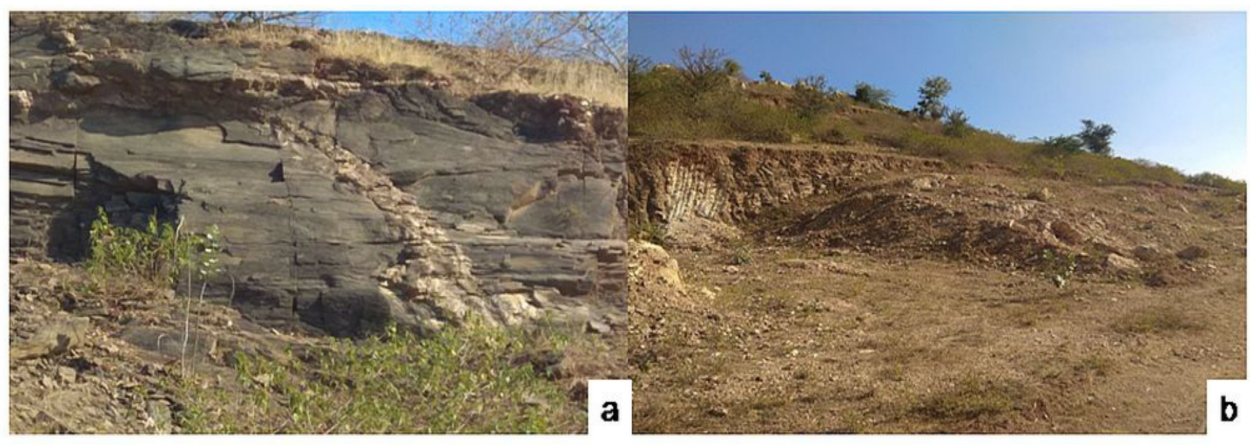

Figure 9. (a) Pegmatitic or silicic intrusion within the BMQ thin section near Gurla. (b) Surface exposures of sericitized altered rock associated with the pegmatite intrusion in the Gurla area as shown in the Figure 8a.

Another evidence of surface imprints of base metal mineralization in the study areas is thepresence of Gossan. A Gossanized zone was identified in the Baran area by the RBD image composite of calcite, sericite, and iron. The Gossanized zone appears blue in the image composite (Figure 10a). Gossanized zones were identified over the calcareous silicates (Figure 10b). We also identified the evidence of structural control around the area on which Gossans were exposed (Figure 10c). We detected the prevalence of goethite and limonite with in calcareous silicates (Figure 11a,b). Some brecciated BMQ were also present (Figure 11c).

We identified the presence of sericitised zone and calcite veining in the Devpura area within the BMQ host rock. We spotteda yellow-coloredsericitized zone within the iron-rich $\mathrm{BMQ}$ in the RBD image composite. The spatial extent of BMQ was delineated using the fit image (Figure 12a,b).We also inferred the traces of axial planar cleavage on the area; this indicates the ductile deformation and mobilization, suitable for the concentration of metals (Figure 12c).In this area, the presence of silicified intrusion was identified with the presence of Bornite-stained BMQ during field validation (Figure 13a-c). 

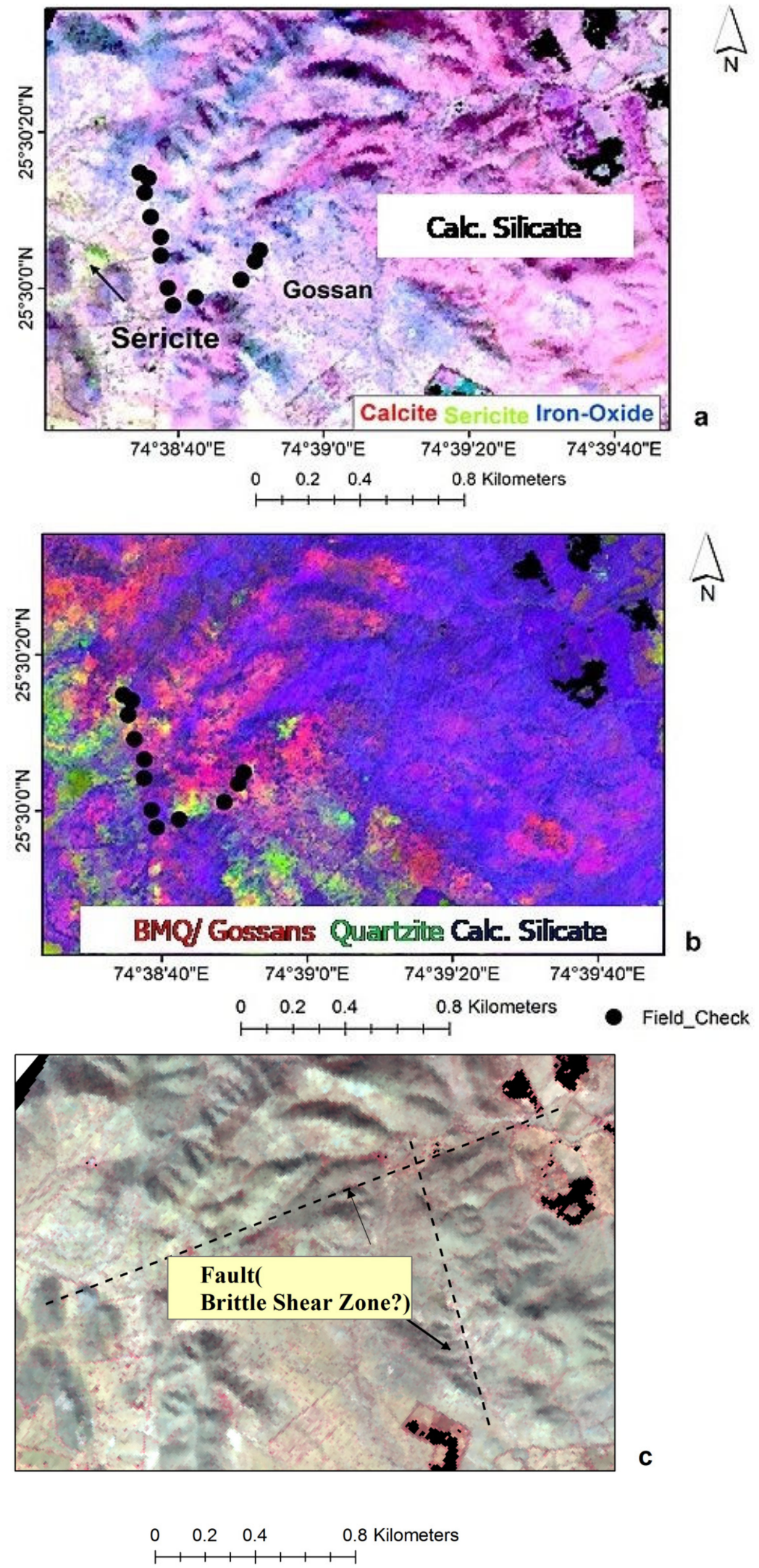

Figure 10. (a) FCC image of calcite, sericite, and Gossan RBDs prepared for Baran area. (b) MRSFFfit image composite developed from the fit images of BMQ, quartzite, and unclassified calcareoussilicates; (c) Some of the linear geological fabric was traced around Gossanized zone in the AVIRIS-NG FCC image. In this image, Red $=950 \mathrm{~nm}$, Green $=650 \mathrm{~nm}$, and Blue $=560 \mathrm{~nm}$. 


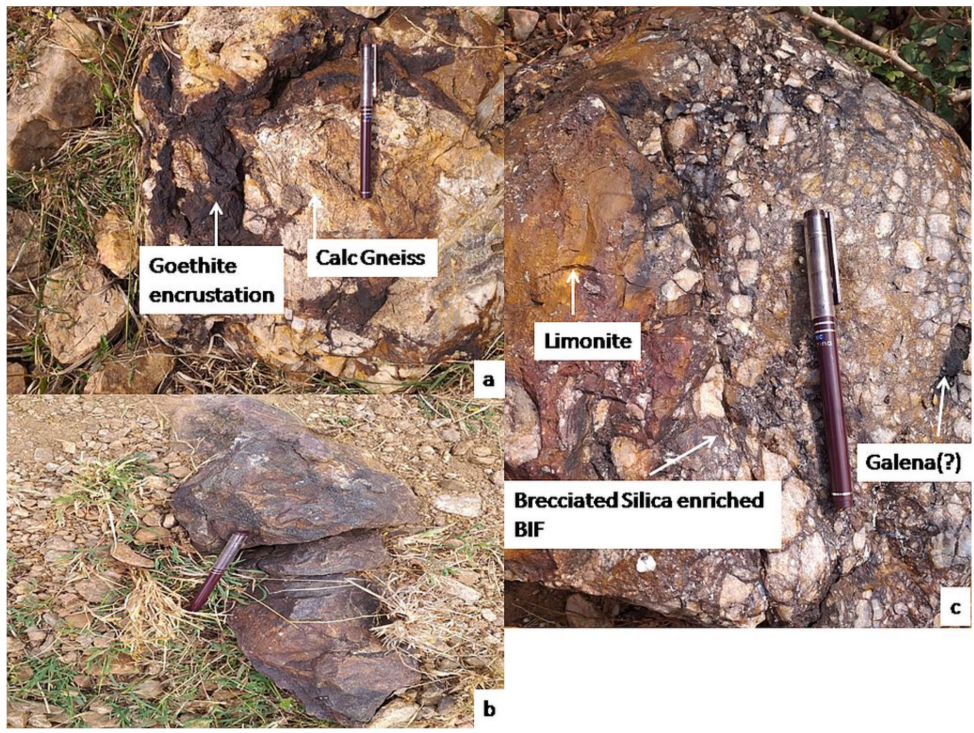

Figure 11. (a) Gossanized (goethite intruded) unclassified calcareous silicates near Baran area. (b) Surface exposures of BMQ, near Baran village. (c) Brecciated and altered BMQ hosting mineralization (presence of Galena, ore of lead), near Baran village.
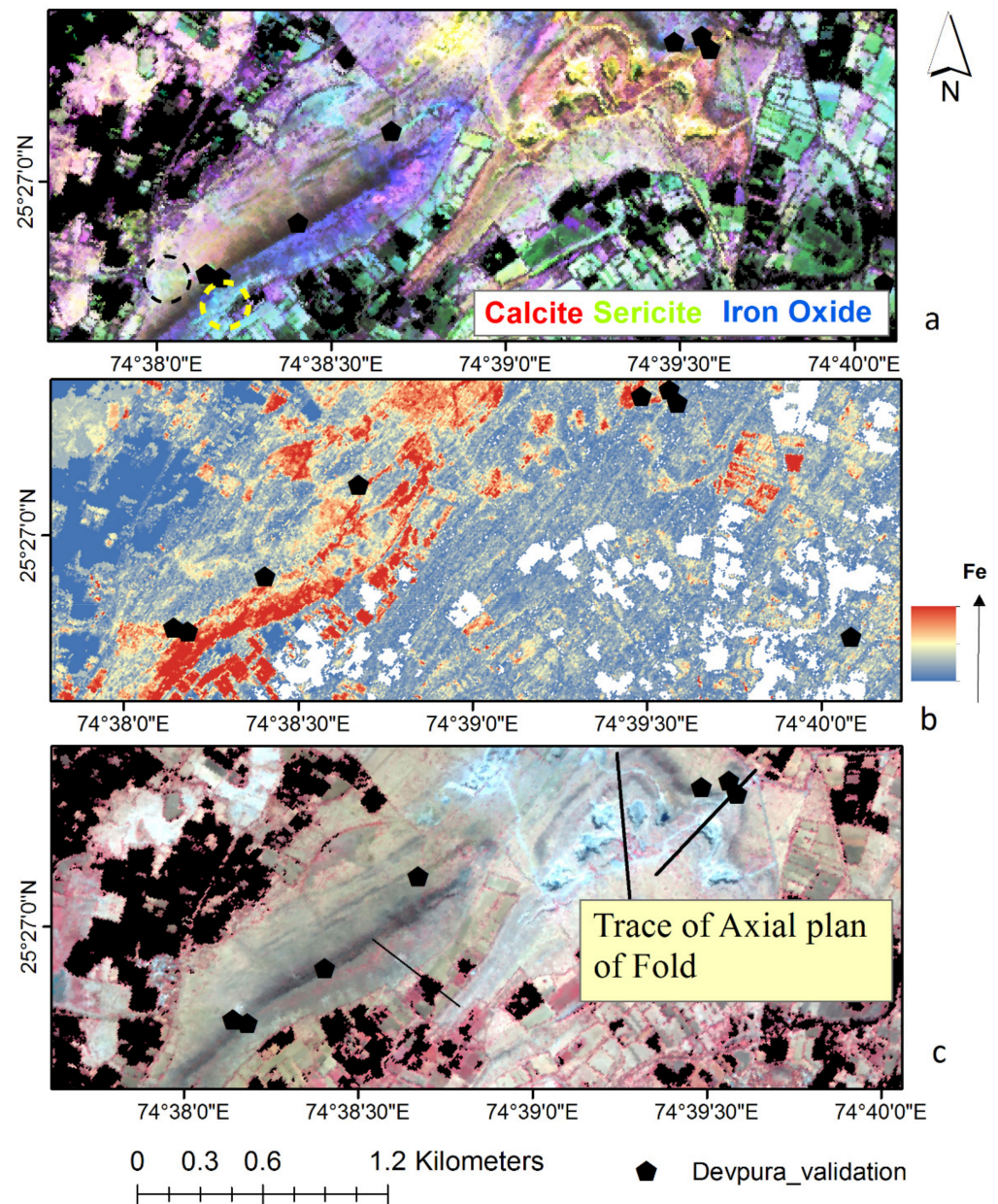

Figure 12. (a) FCC image of calcite, sericite, and Gossan RBDs for Devpura area. Circles are shown to highlight the pegmatite intrusion. (b) Surface exposures of Banded Magnetite Quartzite (BMQ)-rich zones delineated using the thresholdedfit image. (c) Deformational imprints are shown in the FCC image composite of AVIRIS-NG bands. In the AVIRIS image, Red $=850 \mathrm{~nm}$, Green $=650 \mathrm{~nm}$, and Blue $=560 \mathrm{~nm}$. 


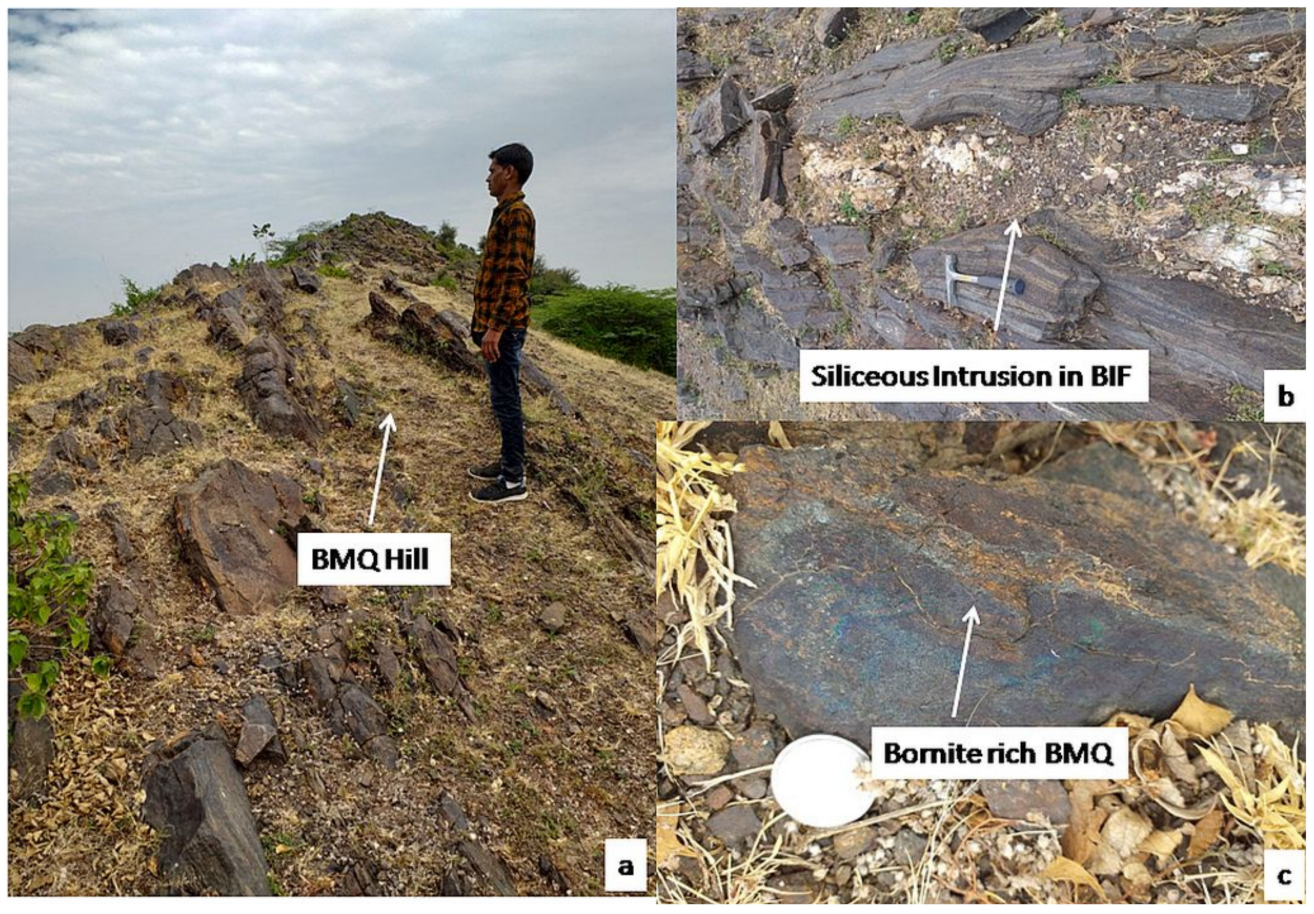

Figure 13. (a) The BMQ hill extending along NE-SW, near Devpura village (see Figure 12 as the reference). (b) The late phase silica intrusions are often associated with mineralization (Cu-sulfide) and is also identified within BMQ. See Figure $12 \mathrm{~b}$ for further reference (c) The surface indications in the form of bornite stains within BMQ, at Devpura village.

In the Lanpriya area, the distribution of major rocks was well delineated using the FCC image composite of the fit image of quartzite, amphibolite, and silicates. The presence of sericitization and Gossanization were identified using FCC prepared using theRBD of surface proxy minerals. We identified the sericitizedzone and Gossans above the quartzite, and this was evident while comparing the fitimage composite of three rock types and the RBD image composite of surface proxy minerals (Figure 14a,b). We also inferred imprints of some linear brittle structures in the AVIRIS-NG composite. In the field, presences of the red oxidized zone of iron oxide mineralswere identified in the sheared quartzite (Figure 15a,b).

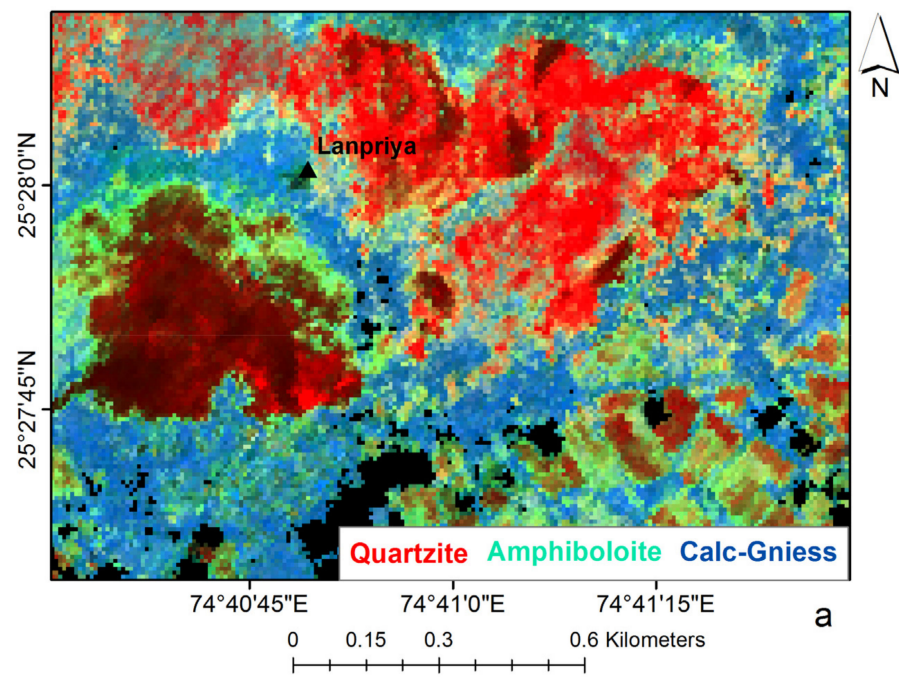

Figure 14. Cont. 

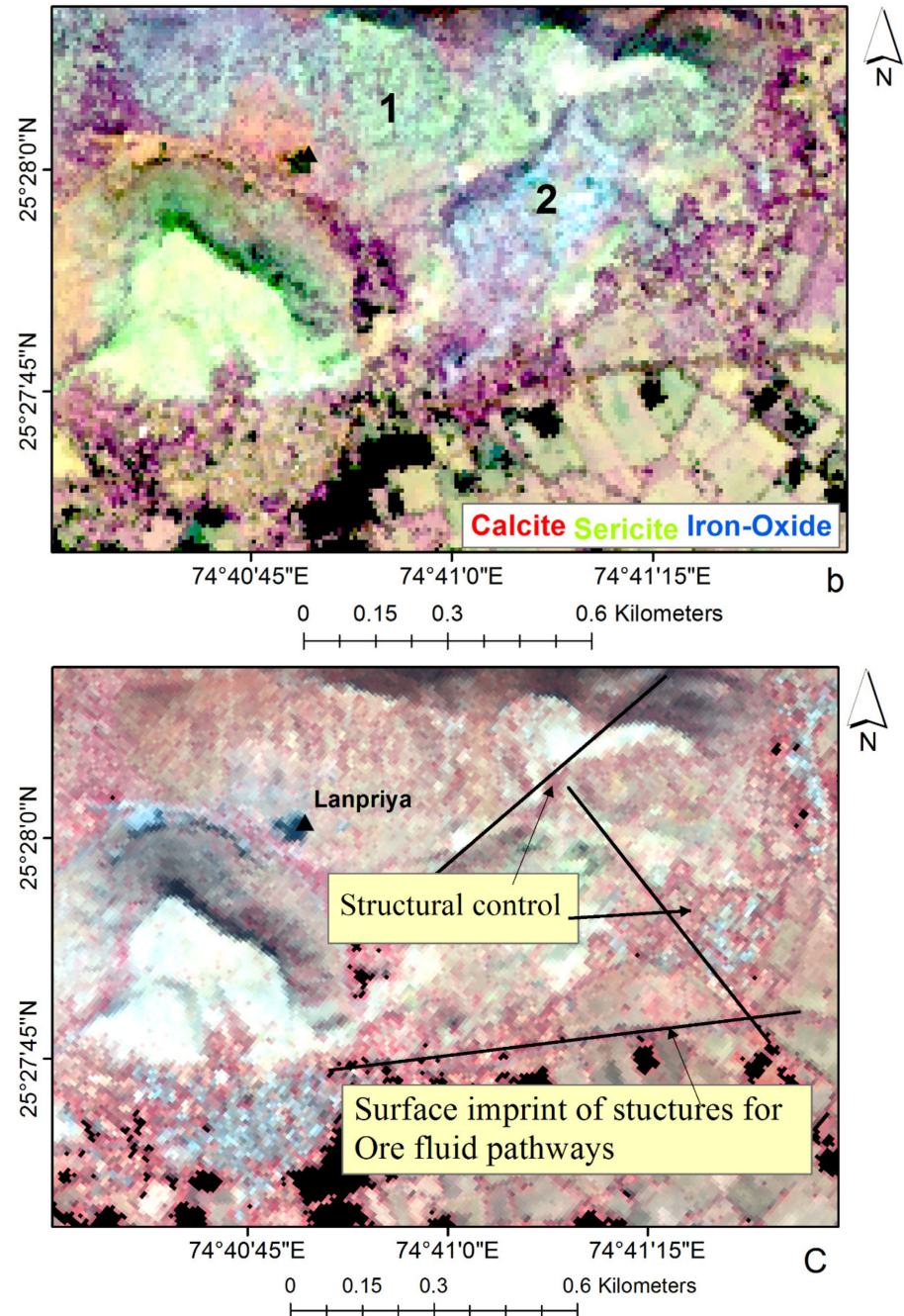

Figure 14. (a) FCC of fit images of multirange SFF algorithms detecting quartzite, amphibolite, and Calc-silicates. (b) Surface imprints of sericitization (1) and Gossanization (2) are also associated with the quartzite. (c) Structural control or the trace of the fault plan which might have facilitated fluid migration in the AVIRIS NG. In the AVIRIS image, Red $=850 \mathrm{~nm}$, Green $=650 \mathrm{~nm}$ and Blue $=560 \mathrm{~nm}$.
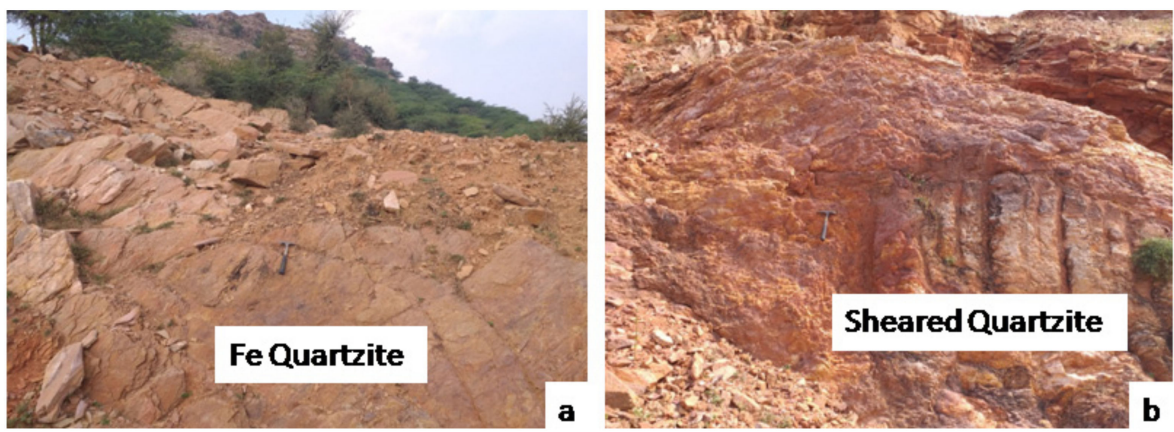

Figure 15. (a) The exposures of foliated and altered Fe rich quartzite near Lanpriya village. (b) The surface exposures of sheared and sericitized Fe-rich quartzite near Lanpriya village.

Surface exposure of calcite-rich veins and sericitized zones were also identified within BMQ at the Mangalpura area (Figure 16a). Calcite-rich zones are pinkish-red, and sericitised zones are green-colored patches within BMQ, which is in turn enhanced with blue color in the RBD image of alteration minerals (Figure 15a). Evidence of ductile deformation was also prominent in this area (Figure 16b). 

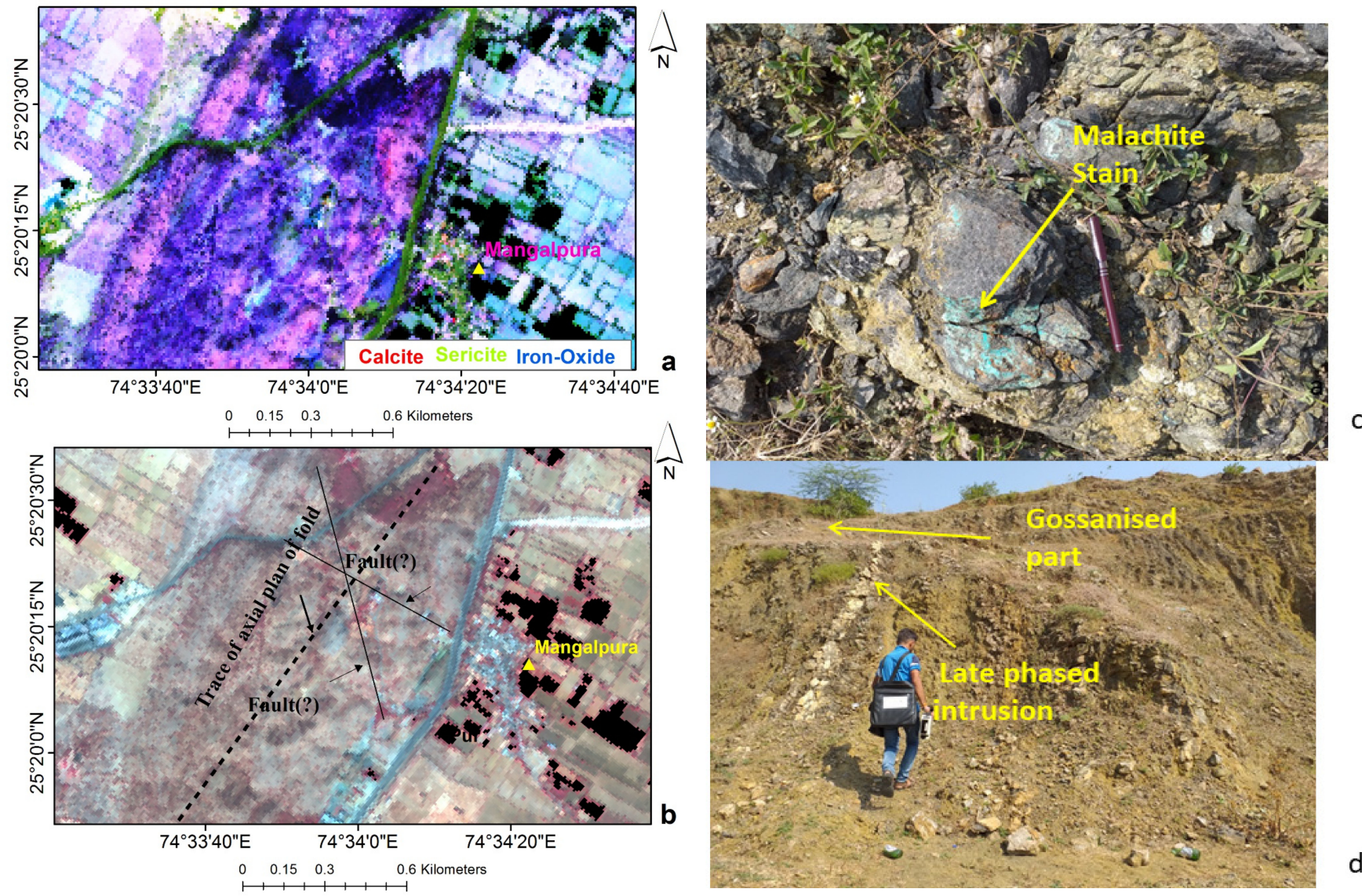

Figure 16. (a) False color image composite map of RBDs prepared for detecting calcite, sericite, and iron oxide are used to these minerals within BMQ around Mangalpur area. (b) FCC image composite of AVIRIS-NG bands are used to show localized geological structures. In the AVIRIS image, Red $=850 \mathrm{~nm}$, Green $=650 \mathrm{~nm}$, and Blue $=560 \mathrm{~nm}$. (c) Malachite stains within BMQ were also identified during field validation. (d) Carbonate-rich sericitized veins were also identified in Mangalpura area.

Evidence of sericitization in quartzite and extensional, ductile structures is coexistent in the Balykhera area (Figures 16b and 17a). We also identified the presence of bornite on the exposed rock in the field within the Gossanized zone, associated predominantly with quartzite (Figures $16 \mathrm{~b}$ and 18a).

\subsection{Synergistic Analysis of Ground Magnetic Data and Surface Distribution of Alteration and Supergene Minerals}

Most of these surface imprints (the locations of altered minerals and Gossanized zones) are aligned along the trend of the large linear structure, which was inferred from the residual magnetic anomaly map (Figure 19). This observation justifies the importance of the identified Gossan and alteration minerals as the possible indicators of localized enrichment of mineralization. This linear fabric is regarded as the suitable pathway for the movement of ore-bearing fluid, responsible for concentrating the mineral deposit. It has been believed that the base metal deposits were formed by convective seawater circulation in zones of crustal extension that traversed the Aravalli fold belt [24]. Surface proxies that occur along with the structures either indicate the imprints of the reaction processes of ore-bearing fluid or indicate the zones of mineral enrichments due to supergene processes. Both of these processes are expected along the linear fabric. Therefore, the spatial proximity of surface proxies of mineralization and linear structural controls of the ore forming process endorses the exploration utility of these surface proxies for finding new deposits. 


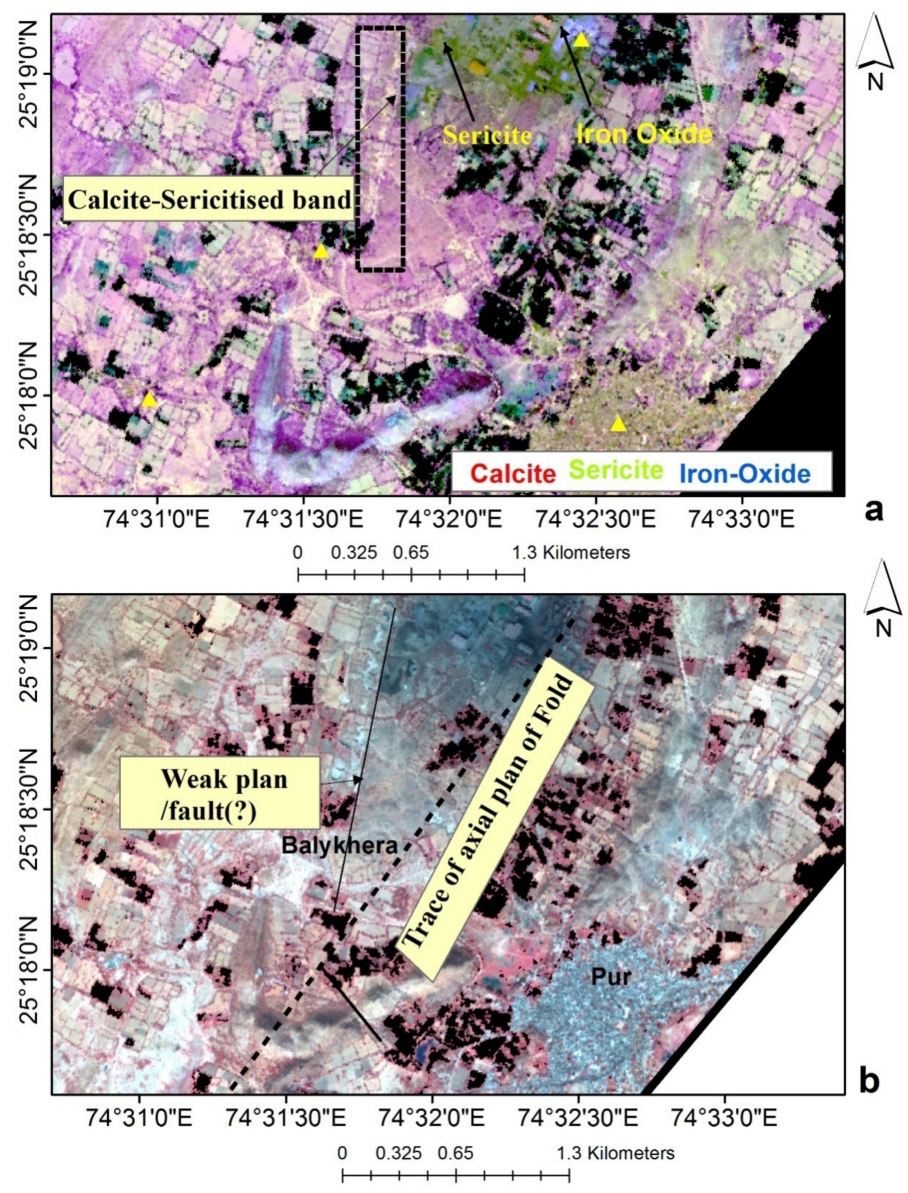

Figure 17. (a) False color composite map of calcite, sericite, and iron oxide RBDs to detect calcitesercite veins within BMQ around Balykhera area (b) FCC image composite of AVIRIS-NG bands showing important structural controls that might have facilitated ore-bearing fluid migration, alteration zone development, and mineral enrichment. In the AVIRIS image, Red $=850 \mathrm{~nm}$, Green $=650 \mathrm{~nm}$, and Blue $=560 \mathrm{~nm}$.

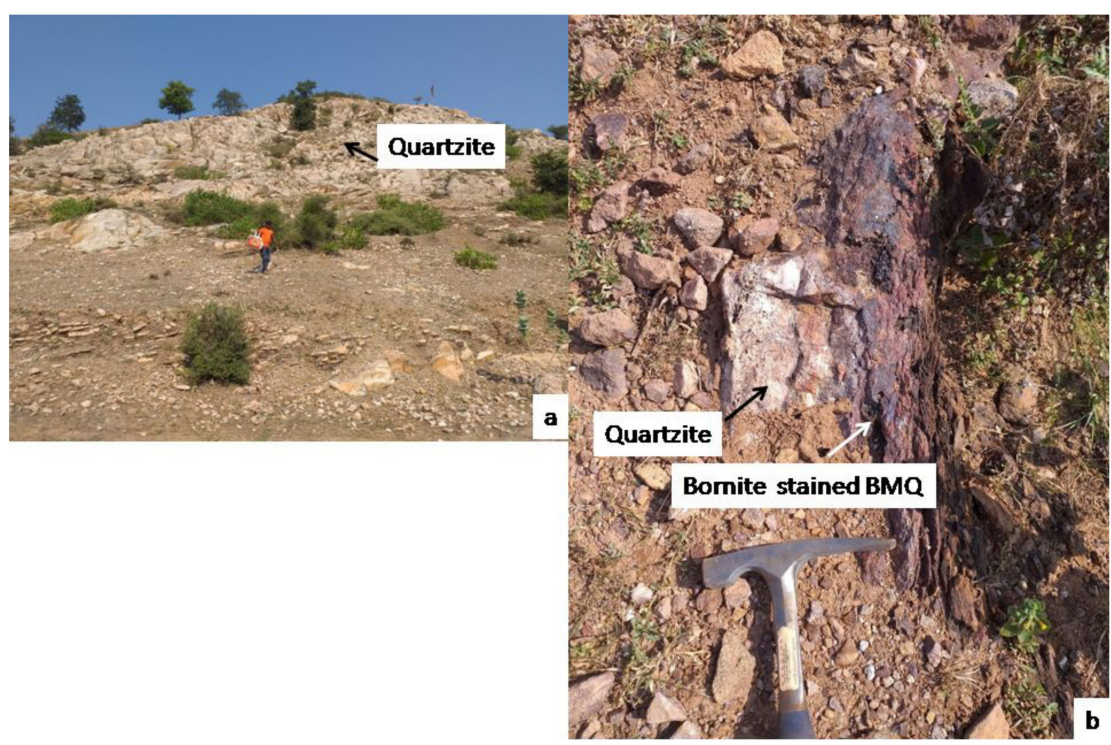

Figure 18. (a) The barrensurface exposures of quartzite hill trending NE-SW, near Balykhera area, Bhilwara district, Rajasthan. (b) The contact between sheared magnetite rich quartzite and BMQ shows surface indications of mineralization near Pur village near Balykhera, Bhilwara district, Rajasthan. 


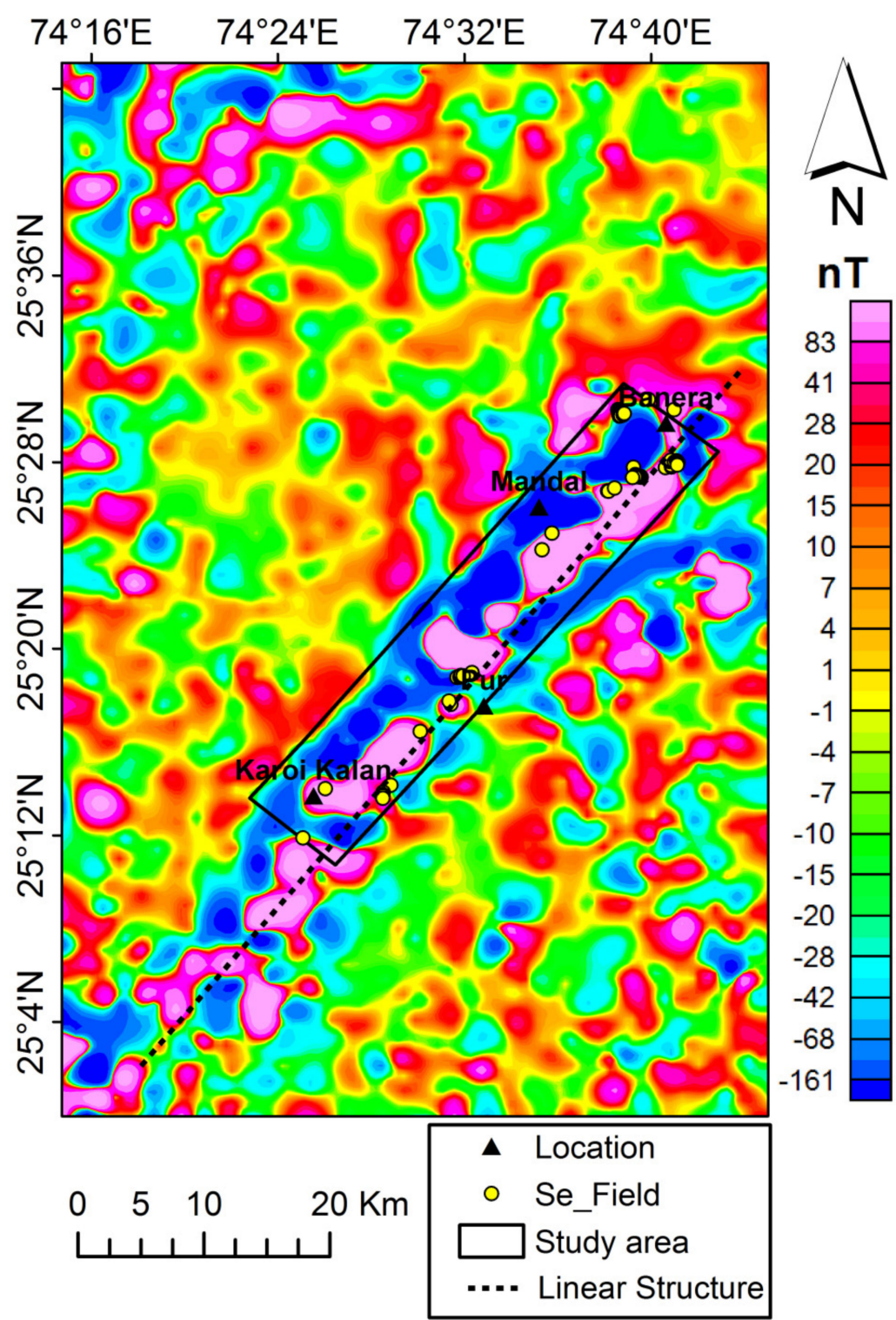

Figure 19. Residual magnetic anomaly map inferring linear structures along the field validated areas with the presence of surface proxies of mineralization (either the presence of Gossan or alteration minerals).

\subsection{Results of XRF and Petrographic Analysis}

It is important to identify the $\mathrm{Cu}-\mathrm{Pb}-\mathrm{Zn}$ enrichment in the rock samples associated with the surface proxies of mineralization. We analyzed the reflected property of rock samples collected from the areas with the evidence of Gossans and alteration minerals using ore microscopic to identify the concentration of sulfides.

We identifiedsulfides in the reflected polished section of the sample in Barran, Balykhera, Mangalpur, and Gurla areas (Figure 20). The XRF analysis of the samples collected from Gurla, Mangalpura, Suras, and Lanpriya showed the enriched Pb, Zn, Cu metal concentrations (Table 3). Mineralogical validation using reflected microscopy and XRF values of $\mathrm{Pb}-\mathrm{Zn}-\mathrm{Cu}$ concentrations confirm the importance of detected surface proxies of mineralization as indicators. Therefore, utilization of high spatial resolution spectral bands of AVIRIS-NG data was essential to delineate the scanty but important mineralization imprints. Some of the surface imprints identified in the areas such as Gurla, Mangalpura, and Lanpriya are associated with localized enrichment of metal, and these areas could be important for identifying pocket loads of base metal. 

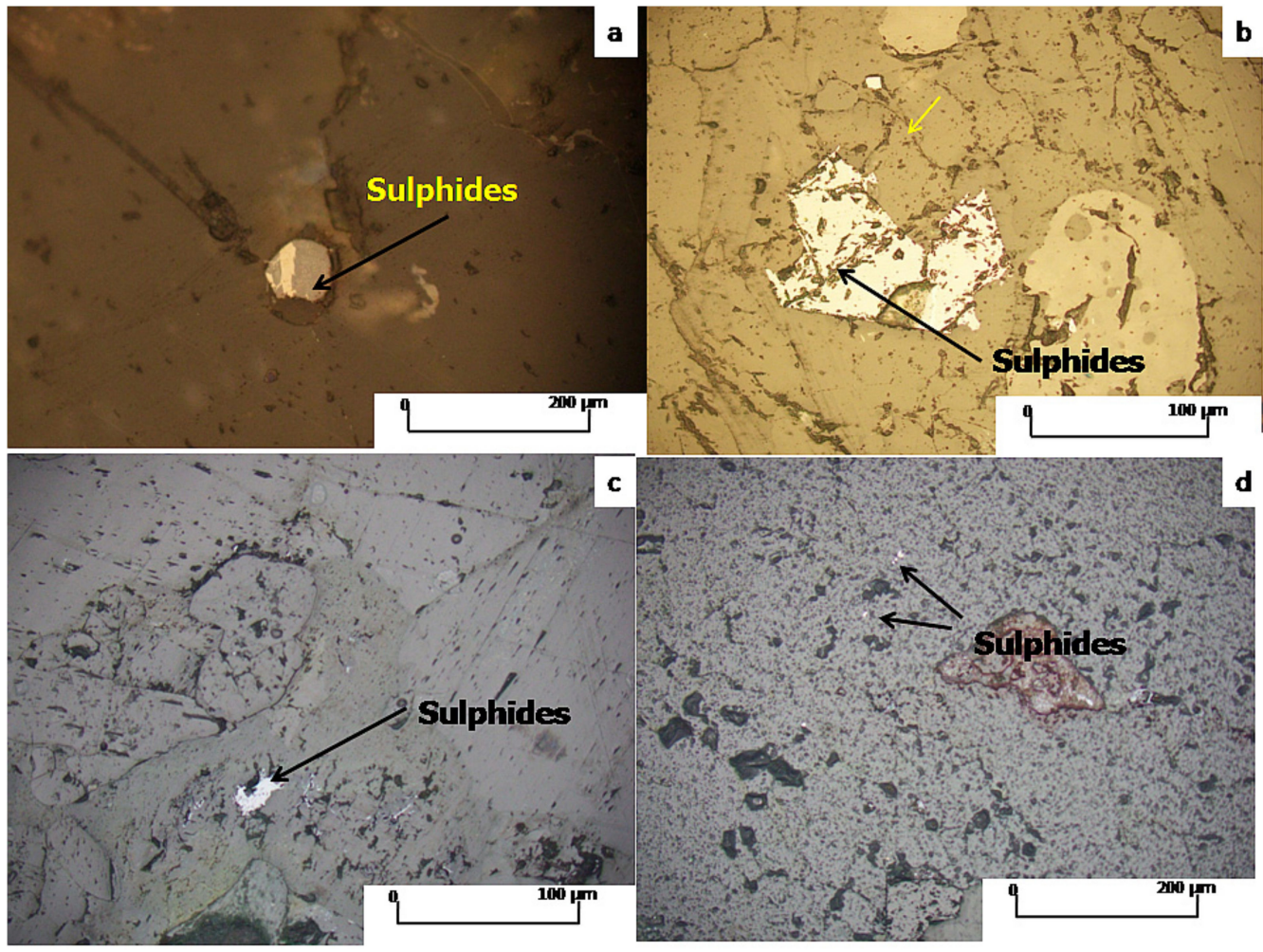

Figure 20. (a) Photomicrograph of sulfide (collected under reflected light) occurring within Quartzite in Mangalpura area. (b) Photomicrograph of sulfide (collected under reflected light) occurring within Balykhera area. (c) Photomicrograph of sulfide (collected under reflected light) occurring within Calcareous Silicates in Baran area. (d) Photomicrograph of Gossanized magnetite rich quartzite (under reflected light) near Gurla village.

Table 3. XRF values of representative samples collected from few important areas around surface.

\begin{tabular}{cccc}
\hline & \multicolumn{2}{c}{ Mean Values of XRF Anomalies for Base Metals (in ppm) } \\
\hline Study Area & $\mathbf{C u}$ & $\mathbf{P b}$ & $\mathbf{Z n}$ \\
\hline Lanpriya & 6286 & 5623 & 2915 \\
Gurla-Momi & 2623 & 12 & 11 \\
Mangalpura & 8438 & 7 & 22 \\
AV 234 & 346 & 685 & 3026 \\
\hline
\end{tabular}

\section{Discussion}

The identified structurally controlled $\mathrm{Pb}-\mathrm{Zn}-\mathrm{Cu}$ deposits from this study are the result of fluid migration associated with the cogenetic fault system [55]. Sometimes, the metal-bearing fluid source was hydrothermal, but the nature and geochemistry of fluids often get modified with the influx of meteoric water [54]. In the literature, convective seawater circulation in the zones of the crustal extension was regarded as responsible for the concentration of metal. The metal content of exhalative brines was precipitated in troughs, where biologic activity was prolific along the zone of crustal extension [56]. The base metal content of exhalative brines was precipitated from convective seawater, which evolved due to marine volcanic exhalation [56].

Most of Proterozoic crustal-scale faults extensional zones arebelieved to bethe important controls of ore mobilization and precipitation [56]. It is understood that the $\mathrm{Pb}, \mathrm{Zn}$, and $\mathrm{Cu}$ are preferentially partitioned into the late phase fluid. The degree of partitioning depends on the chlorine, the water content in the melt, the relationship between the vapor phase separation, and the crystallization of magma [57]. The acidic solutions often have $\mathrm{pH}$ within the range of 1.4 to 2.2; such solutions react with a variety of wall rock 
and move towards super-saturation in terms of base metal concentration [57]. Therefore, the surface indication alterations caused by late phase fluid are also expected with base metal mineralization.

In the Pur-Banerastudy area, surface signatures related to the late phase fluid migration are common, and these signatures are identified in places such as the Gurla and Devpura areas. In general, the deposit grade is low and few isolated ( $\mathrm{Cu}-\mathrm{Pb}-\mathrm{Zn})$ deposits are reported in the basal sequence of the Aravalli Group [58].

However, there are possibilities to identify the additional pockets of deposits based on the results of this study. AVIRIS-NG data used here provide an excellent high-resolution map of surface proxies of mineralization by delineating the surface alteration zone and cap rock of mineralization. A few localized anomalies of alteration and supergene enrichment were identified from this study. Some of these localized and patchy surface proxies of mineralization are difficult to be detected using coarse spatial and spectral resolution spaceborne hyperspectral data.

This study identified the surface signatures of $\mathrm{Cu}-\mathrm{Pb}-\mathrm{Zn}$ mineralization by identifying the Gossans above calcareous silicate rocks and quartzite. These Gossans are indicative of base metal deposits, as calcareoussilicates and quartzites are both iron-poor rock. These signatures are prominent in the Baran, Lanpriya, and Mangalpura areas. On the other hand, the presence of malachite, bornite, and sericitized pegmatitic veins identified in Gurla, Devpura, indicate base metal enrichment in the BMQ. Most of the identified areas of surface proxies (Fe-oxidation, Gossans, and sericitization) are along the regional extensional zone, which is an important locale for late-phase fluid activity and ore deposition [59]. The ground magnetic study confirmed the presence of the regional extensional zone as linear discontinuity.

These surface anomalies are important to identify the pocket deposits in this mineralized province, provided these surface alterations are verified in light ofthe ore genetic model of base metal formation in the present geological province. In this study, the evidence of mineral enrichment was confirmed using several supporting data, including ore microscopyand XRF. A detailed account of the magnetic anomalies associated with the different base metal deposit and theirutilization are discussed in the literature [60]. In general, massive sulfide bodies show an increasingmagnetic response with the presence of an increasing amount of magnetic minerals [61,62]. Recent research discussed the importance of ground magnetic data to identify the structural control of base metal deposits [54].

In the present study, we also found that all the surface imprints of mineralization and their associated high $\mathrm{Pb}-\mathrm{Zn}-\mathrm{Cu}$ anomaly are associated with a NE-SW trending structure. We identified the imprints of shearing along this structure at the places such as Lanpriya and Baran, as host rocks had imprinted shearing and brecciation (Figures 11c and 15c). We also identified ductile structures in the Devpura area (Figures 12b and 15b). Most of these localized structures are the result of shearing operated along the linear structural fabric. The shearing might have resulted in localized brittle and ductile structures based on the depth of influence of shearing and the related changes in the rheological properties of the rock.

The identification of surface imprints of mineralization along the structural control confirmsthat structural controls can be potential indicators of base metal enrichment. In most of these sites, surface imprints of altered rocks are associated with the localized fault. The potential of the identified surface signatures as the mineralization indicator is further confirmed by the high concentration of $\mathrm{Cu}, \mathrm{Pb} \mathrm{Zn}$ in the samples collected from the study area (Table 3).

\section{Conclusions}

The present study has brought out the following aspects of airbornehyperspectral imaging utilization for base metal exploration:

1. The identified spectral anomalies in a 1:10000 scale would provide a valuable exploration guide to explore discrete mineralized areas, which are extended along a structure trending NW-SE direction. These isolated, patchy surface proxies are importantfor detecting the localized enrichment of metals. 
2. Conjugate use of MRSFF image productsfor delineating rock types and RBD image products for identifying surface mineralizationproved suitable to establish the relation between rock types and associated surface proxies of mineralization. For example, Gossans are formed above the calcareous silicates and quartzite, whereas serictization and carbonation are prominent over BMQ and quartzite.

3. Some ofthe surface mineral proxies had high XRF values indicative ofpromising high metal concentration. The spatial alignment of thesealteration zones or surface proxies along the structural fabricmakesthe occurrences of these surface proxies suitable for detailed exploration, as previous studies attributed the role of longitudinal structure in metal concentration in this area.

Author Contributions: Conceptualization, A.G.; methodology, A.G.; software, A.G., N.K.B.; validation, U.K.G., J.S., R.B. and A.G.; investigation, A.G., U.K.G., J.S. and R.B.; resources, A.G., R.B., K.V.K., P.V.N.R. and A.B.P.; formal analysis, A.G., U.K.G., J.S. and N.R.; data curation, A.G.; writing, A.G.; writing-review and editing, S.C., R.B., U.K.G. and A.B.P.; visualization, A.G., A.B.P. and S.C.; supervision, P.V.N.R. and N.R.; project administration, K.V.K. and P.V.N.R. All authors have read and agreed to the published version of the manuscript.

Funding: This research received no external funding.

Data Availability Statement: AVIRIS-NG data used here can be downloaded from https:/ /vedas. sac.gov.in/aviris_web/ (accessed on 24 February 2020).

Acknowledgments: Authors are thankful to Director General, GSI and Director, NRSC for approving the collaborative project for investigating the potential of airborne hyperspectral data in mineral exploration.

Conflicts of Interest: The authors declare no conflict of interest.

\section{References}

1. Guha, A.; Chatterjee, S.; Ooman, T.; Kumar, K.V. Synergistic use of ASTER, L-band ALOS PALSAR and hyperspectral AVIRIS-NG data for geoexploration of lode type gold deposit-A study in HuttiMaski Schist Belt, India. Ore Geol. Rev. 2020, in press. [CrossRef]

2. Guha, A.; Mondal, S.; Chatterjee, S.; Kumar, K.V. Airborne imaging spectroscopy of igneous layered complex and their mapping using different spectral enhancement conjugated support vector machine models. Geocarto Int. 2020, 1-17. [CrossRef]

3. Bhattacharya, S.; Kumar, H.; Guha, A.; Dagar, A.K.; Pathak, S.; Pasricha, K.R.; Mondal, S.; Kumar, K.V.; Farrand, W.; Chatterjee, S.; et al. Potential of airborne hyperspectral data for geo-exploration over parts of different geological/metallogenic provinces in India based on AVIRIS-NG observations. Curr. Sci. 2019, 116, 1143-1156. [CrossRef]

4. Kumar, C.; Chatterjee, S.; Oommen, T. Mapping hydrothermal alteration minerals using high-resolution AVIRIS-NG hyperspectral data in the Hutti-Maski gold deposit area, India. Int. J. Remote Sens. 2020, 41, 794-812. [CrossRef]

5. Rani, K.; Guha, A.; Kumar, K.V.; Bhattacharya, B.K.; Pradeep, B. Potential use of airborne hyperspectral AVIRIS-NG data for mapping proterozoicmetasediments in Banswara, India. J. Geol. Soc. India 2020, 95, 152-158. [CrossRef]

6. Bhattacharya, B.K.; Green, R.O.; Rao, S.; Saxena, M.; Sharma, S.; Kumar, K.A.; Srinivasulu, P.; Sharma, S.; Dhar, D.; Bandyopadhyay, S.; et al. An overview of AVIRIS-NG airborne hyperspectral science campaign over India. Curr. Sci. 2019, 116, 1082-1088. [CrossRef]

7. Rockwell, B.W. Comparison of ASTER- and AVIRIS-Derived Mineral and Vegetation Maps of the White Horse Replacement Alunite Deposit and Surrounding Area, Marysvale Volcanic Field, Utah; Scientific Investigations Report 2009-5117; U.S. Geological Survey: Reston, VA, USA, 2009; 31p.

8. Kruse, F.A.; Boardman, J.W.; Huntington, J.F. Comparison of airborne hyperspectral data and EO-1 Hyperion for mineral mapping. IEEE Trans. Geosci. Remote Sens. 2003, 41, 1388-1400. [CrossRef]

9. Kruse, F.A. Mineral mapping with AVIRIS and EO-1 Hyperion. In Proceedings of the 12th JPL Airborne Geoscience Workshop, Pasadena, CA, USA, 12-16 January 1998; pp. 24-28.

10. Sara, S.; Christian, M.; Christian, R. Mapping ultramafic complexes using airborne imaging spectroscopy and space-borne data in Arctic regions with abundant lichen cover, a case study from the Niaqornarssuit complex in South West Greenland. Eur. J. Remote Sens. 2020, 53, 156-175.

11. Kumar, C.; Chatterjee, S.; Oommen, T.; Guha, A. Automated lithological mapping by integrating spectral enhancement techniques and machine learning algorithms using AVIRIS-NG hyperspectral data in Gold-bearing granite-greenstone rocks in Hutti, India. Int. J. Appl. Earth Obs. Geoinf. 2020, 86, 102006. [CrossRef]

12. Sekandari, M.; Masoumi, I.; Pour, A.B.; Muslim, A.M.; Hossain, M.S.; Misra, A. ASTER and WorldView-3 satellite data for mapping lithology and alteration minerals associated with Pb-Zn mineralization. Geocarto Int. 2020, 1-31. [CrossRef]

13. Vedas. 2021. Available online: https://vedas.sac.gov.in/aviris_web/ (accessed on 24 February 2020). 
14. Govil, H.; Gill, N.; Rajendran, S.; Santosh, M.; Kumar, S. Identification of new base metal mineralization in Kumaon Himalaya, India, using hyperspectral remote sensing and hydrothermal alteration. Ore Geol. Rev. 2018, 92, 271-283. [CrossRef]

15. Mielke, C.; Muedi, T.; Papenfuß, A.; Boesche, N.K.; Rogass, C.; Gauert, C.D.K.; Altenberger, U.; de Wit, M.J. Multi-and hyperspectral spaceborne remote sensing of the Aggeneys base metal sulphide mineral deposit sites in the Lower Orange River region, South Africa. S. Afr. J. Geol. 2016, 119, 63-76. [CrossRef]

16. Zabcic, N.; Rivard, B.; Ong, C.; Mueller, A. Using airborne hyperspectral data to characterize the surface $\mathrm{pH}$ and mineralogy of pyrite mine tailings. Int. J. Appl. Earth Obs. Geoinf. 2014, 32, 152-162. [CrossRef]

17. Thornber, M.; Wildman, J. Supergene alteration of sulphides, VI. The binding of $\mathrm{Cu}, \mathrm{Ni}, \mathrm{Zn}, \mathrm{Co}$ and Pb with gossan (iron-bearing) minerals. Chem. Geol. 1984, 44, 399-434. [CrossRef]

18. Suárez, S.; Prichard, H.M.; Velasco, F.; Fisher, P.C.; McDonald, I. Alteration of platinum-group minerals and dispersion of platinum-group elements during progressive weathering of the Aguablanca Ni-Cu deposit, SW Spain. Miner. Depos. 2010, 45, 331-350. [CrossRef]

19. Zhao, X.F.; Zhou, M.F. Fe-Cu deposits in the Kangdian region, SW China: A Proterozoic IOCG (iron-oxide-copper-gold) metallogenic province. Miner. Depos. 2011, 46, 731-747. [CrossRef]

20. Bharktya, D.; Gupta, R. Regional tectonics and sulphide ore localisation in Delhi-Aravalli belt, Rajasthan, India-Use of LANDSAT imagery. Adv. Space Res. 1981, 1, 299-302. [CrossRef]

21. Basu, K.K. Base metal mineralisation along the Pur-Banera belt, Bhilwara district, Rajasthan. Misc. Publ. Geol. Surv. India 1971, 16 153-159.

22. D'Souza, J.; Prabhakar, N.; Xu, Y.; Sharma, K.K.; Sheth, H. Mesoarchaean to Neoproterozoic (3.2-0.8 Ga) crustal growth and reworking in the Aravalli Craton, northwestern India: Insights from the Pur-Banera supracrustal belt. Precambrian Res. 2019, 332, 105383. [CrossRef]

23. Shaji, T.S.; Desapati, T.; Fahmi, S.; Yadav, G.S.; Pande, A.K. Occurrence of uraninite and brannerite in the Samarkiya area, Bhilwara district, Rajasthan. Curr. Sci. 2007, 92, 592-594.

24. Deb, M.; Sarkar, S. Proterozoic tectonic evolution and metallogenesis in the Aravalli-Delhi orogenic complex, northwestern India. Precambrian Res. 1990, 46, 115-137. [CrossRef]

25. Banerjee, P.K.; Ghosh, S. Copper, lead and zinc. Rec. Geol. Surv. India 1972, 102, 41-50.

26. GSI. Geology and Mineral Resources of Rajasthan, 3rd ed.; No. 30, Part 12; Miscellaneous Publication: Albuquerque, NM, USA, 2011.

27. Bue, B.D.; Thompson, D.R.; Eastwood, M.; Green, R.O.; Gao, B.-C.; Keymeulen, D.; Sarture, C.M.; Mazer, A.S.; Luong, H.H. Real-time atmospheric correction of AVIRIS-NG imagery. IEEE Trans. Geosci. Remote Sens. 2015, 53, 6419-6428. [CrossRef]

28. Guha, A.; Chakraborty, D.; Ekka, A.B.; Pramanik, K.; Kumar, K.V.; Chatterjee, S.; Subramanium, S.; Rao, D.A. Spectroscopic study of rocks of Hutti-Maski schist belt, Karnataka. J. Geol. Soc. India 2012, 79, 335-344. [CrossRef]

29. Milton, E.J.; Schaepman, M.E.; Anderson, K.; Kneubahler, M.; Fox, N. Progress in field spectroscopy. Remote Sens. Environ. 2009, 113, 92-109. [CrossRef]

30. Baldridge, A.M.; Hook, S.J.; Grove, C.I.; Rivera, G. The ASTER spectral library version 2.0. Remote Sens. Environ. 2009, 113, 711-715. [CrossRef]

31. Biggar, S.F.; Labed, J.; Santer, R.P.; Slater, P.N.; Jackson, R.D.; Moran, M.S. Laboratory Calibration of Field Reflectance Panels. In Proceedings of the Recent Advances in Sensors, Radiometry, and Data Processing for Remote Sensing, Orlando, FL, USA, 6-8 April 1988; SPIE: Bellingham, WA, USA, 1988.

32. Nicodemus, F.E. Reflectance nomenclature and directional reflectance and emissivity. Appl. Opt. 1970, 9, 1474-1475. [CrossRef]

33. GSM. GSM-Proton Precision Magnetometer. 2021. Available online: http://www.gemsys.ca/pdf/GSM_19T.pdf (accessed on 12 January 2021).

34. Pan Analytic. 2021. Available online: https://www.malvernpanalytical.com/ (accessed on 6 February 2021).

35. Guha, A.; Rao, D.A.; Ravi, S.; Kumar, K.V.; Rao, E.D. Analysis of the potential of kimberlite rock spectra as spectral end member using samples from Narayanpet Kimberlite Field, Andhra Pradesh. Curr. Sci. 2012, 103, 1096-1104.

36. Guha, A.; Kumar, K.V.; Porwal, A.; Rani, K.; Sahoo, K.; Kumar, S.A.; Singaraju, V.; Singh, R.; Khandelwal, M.; Raju, P.; et al. Reflectance spectroscopy and ASTER based mapping of rock-phosphate in parts of Paleoproterozoic sequences of Aravalli group of rocks, Rajasthan, India. Ore Geol. Rev. 2019, 108, 73-87. [CrossRef]

37. Shanmugam, S.; Srinivasaperumal, P. Spectral matching approaches in hyperspectral image processing. Int. J. Remote Sens. 2014, 35, 8217-8251. [CrossRef]

38. Clark, R.N.; Swayze, G.A.; Livo, K.E.; Kokaly, R.; Sutley, S.J.; Dalton, J.B.; McDougal, R.R.; Gent, C.A. Imaging spectroscopy: Earth and planetary remote sensing with the USGS Tetracorder and expert systems. J. Geophys. Res. Space Phys. 2003, 108, 1-44. [CrossRef]

39. Clark, R.N. Spectroscopy of rocks and minerals, and principles of spectroscopy. In Manual of Remote Sensing: Remote Sensing for the Earth Sciences; John Wiley \& Sons: New York, NY, USA, 1999; Volume 3, pp. 2-58.

40. Guha, A.; Ghosh, B.; Chaudhury, S.; Rani, K.; Kumar, K.V. Spectral response of few important textural variants of chromitite and its potential in estimating relative grades of chromitite-A case study for chromitite of Nuggihalli Schist Belt, India. Curr. Sci. 2018, 114, 1721. [CrossRef]

41. Smith, R.E.; Singh, B. Recognizing, in lateritic cover, detritus shed from the Archaean Gossan Hill Cu-Zn-Au volcanic-hosted massive sulphide deposit, Western Australia. Geochem. Explor. Environ. Anal. 2007, 7, 71-86. [CrossRef] 
42. Thébault, E.; Finlay, C.C.; Beggan, C.D.; Alken, P.; Aubert, J.; Barrois, O.; Bertrand, F.; Bondar, T.; Boness, A.; Brocco, L.; et al. International geomagnetic reference field: The 12th generation. Earth Planets Space 2015, 67, 79. [CrossRef]

43. Baranov, V. A new method for interpretation of aeromagnetic maps: Pseudo-gravimetric anomalies. Geophysics 1957, $22,359-382$. [CrossRef]

44. Roest, W.R.; Pilkington, M. Identifying remanent magnetization effect in magnetic data. Geophysics 1993, 58, 653-659. [CrossRef]

45. Spector, A.; Grant, F.S. Statistical methods for interpreting aeromagnetic data. Geophysics 1970, 35, 293-302. [CrossRef]

46. Roy, A.; Aina, A.O. Some new magnetic transformations. Geophys. Prospect. 1986, 34, 1219-1232. [CrossRef]

47. Blakely, R.J. Potential Theory in Gravity and Magnetic Applications; Cambridge University Press Science: London, UK, 1995.

48. Guo, L.; Meng, X.; Chen, Z.; Li, S.; Zheng, Y. Preferential filtering for gravity anomaly separation. Comput. Geosci. 2013, 51, 247-251. [CrossRef]

49. Taggart, J.E., Jr.; Siems, D.F. Major Element Analysis by Wavelength Dispersive X-ray Fluorescence Spectrometry; U.S. Geological Survey Open-File Report 02-223-T; U.S. Geological Survey: Reston, VA, USA, 2002; pp. T1-T9.

50. Taggart, J.E., Jr.; Lindsey, J.R.; Scott, B.A.; Vivit, D.V.; Bartel, A.J.; Stewart, K.C. Analysis of geologic materials by wavelengthdispersive X-ray fluorescence spectrometry. In Methods for Geochemical Analyses; Baedecker, P.A., Ed.; U.S. Geological Survey Professional Paper 1770; U.S. Geological Survey: Reston, VA, USA, 1987; pp. E1-E19.

51. Longhi, I.; Sgavetti, M.; Chiari, R.; Mazzoli, C. Spectral analysis and classification of metamorphic rocks from laboratory reflectance spectra in the 0.4-2.5 $\mu \mathrm{m}$ interval: A tool for hyperspectral data interpretation. Int. J. Remote Sens. 2001, 22, 3763-3782. [CrossRef]

52. Kokaly, R.F.; Clark, R.N.; Swayze, G.A.; Livo, K.E.; Hoefen, T.M.; Pearson, N.C.; Wise, R.A.; Benzel, W.M.; Lowers, H.A.; Driscoll, R.L.; et al. USGS Spectral Library Version 7: Data Series 1035; U.S. Geological Survey: Reston, VA, USA, $2017 ;$ p. 61.

53. Crowley, J.K.; Brickey, D.W.; Rowan, L.C. Airborne imaging spectrometer data of the Ruby Mountains, Montana: Mineral discrimination using relative absorption band-depth images. Remote Sens. Environ. 1989, 29, 121-134. [CrossRef]

54. Sugden, T.J.; Deb, M.; Windley, B.F. The tectonic setting of mineralisation in the Proterozoic Aravalli Delhi Orogenic belt, NW India. Dev. Precambrian Geol. 1990, 8, 367-390.

55. Zhai, D.-G.; Liu, J.-J.; Wang, J.-P.; Yao, M.-J.; Wu, S.-H.; Fu, C.; Liu, Z.-J.; Wang, S.-G.; Li, Y.-X. Fluid evolution of the Jiawula Ag-Pb-Zn deposit, Inner Mongolia: Mineralogical, fluid inclusion, and stable isotopic evidence. Int. Geol. Rev. 2013, 55, 204-224. [CrossRef]

56. Holland, H.D. Granites, solutions, and base metal deposits. Econ. Geol. 1972, 67, 281-301. [CrossRef]

57. Porwal, A.; Carranza, E.J.M.; Hale, M. Tectonostratigraphy and base-metal mineralization controls, Aravalli province (Western India): New interpretations from geophysical data analysis. Ore Geol. Rev. 2006, 29, 287-306. [CrossRef]

58. Yadav, S.; Porwal, A. Controls on SEDEX mineralization in the Aravalli-Delhi Fold Belt: Insights from integrated 3D geological and geophysical modelling. In Proceedings of the EGU General Assembly Conference, Vienna, Austria, 23-28 April 2017; Volume 19, p. 1529.

59. Hood, P.J.; Holroyd, M.T.; McGrath, P.H. Magnetic methods applied to base metal exploration. In Geophysics and Geochemistry in the Search for Metallic Ores; Hood, P.J., Ed.; Geological Survey of Canada, Economic Geology: Montreal, Canada, 1979; pp. 77-104.

60. Whiteley, R.J. (Ed.) Geophysical Case History of the Woodlawn Orebody; Pergamon Press: New South Wales, Australia, 1981 ; p. 588.

61. Clark, D.; Tonkin, C. Magnetic anomalies due to pyrrhotite: Examples from the Cobar area, N.S.W., Australia. J. Appl. Geophys. 1994, 32, 11-32. [CrossRef]

62. Kumar, K.S.; Begum, S.P.; Srinivas, G.S.; Rao, M.S.H.; Prasad, P.P.; Seshunarayna, T.; Tiwari, R.K. Spectral analysis of magnetic data in the Ajmer-Sambar Sector, North-Central Rajasthan. J. Geol. Soc. India. 2018, 92, 368-372. [CrossRef] 